\title{
Three-Dimensional Ordered Mesoporous Carbon Spheres Modified with Ultrafine Zinc Oxide \\ Nanoparticles for Enhanced Microwave Absorption \\ Properties
}

Cite as

Nano-Micro Lett.

(2021) 13:76

Received: 20 October 2020

Accepted: 28 December 2020

Published online: 17 February 2021

(C) The Author(s) 2021

\author{
Yan Song ${ }^{1}$, Fuxing Yin $^{1}$, Chengwei Zhang ${ }^{1}{ }^{\bowtie}$, Weibing Guo ${ }^{1}{ }^{凶}$, Liying Han ${ }^{1}$, \\ Ye Yuan ${ }^{1} \bowtie$
}

\section{HIGHLIGHTS}

- Three-dimensional ordered mesoporous carbon spheres modified with ultrafine zinc oxide nanoparticles are successfully prepared.

- The microwave absorbing performance of zinc oxide/carbon nanocomposites can be controlled through regulating ratio of zinc oxide nanoparticles.

- Electromagnetic simulation of radar cross section on a complicated groove structure demonstrates the microwave absorbing ability of the carbon based nanocomposites.

ABSTRACT Currently, electromagnetic radiation and interference have a significant effect on the operation of electronic devices and human health systems. Thus, developing excellent microwave absorbers have a huge significance in the material research field. Herein, a kind of ultrafine zinc oxide ( $\mathrm{ZnO}$ ) nanoparticles (NPs) supported on three-dimensional (3D) ordered mesoporous carbon spheres ( $\mathrm{ZnO} / \mathrm{OMCS}$ ) is prepared from silica inverse opal by using phenolic resol precursor as carbon source. The prepared lightweight $\mathrm{ZnO} / \mathrm{OMCS}$ nanocomposites exhibit 3D ordered carbon sphere array and highly dispersed ultrafine $\mathrm{ZnO}$ NPs on the mesoporous cell walls of carbon spheres. ZnO/OMCS-30 shows microwave absorbing ability with a strong absorption $(-39.3 \mathrm{~dB}$ at $10.4 \mathrm{GHz}$ with a small thickness of $2 \mathrm{~mm}$ ) and a broad effective absorption bandwidth $(9.1 \mathrm{GHz})$. The outstanding microwave absorbing ability benefits

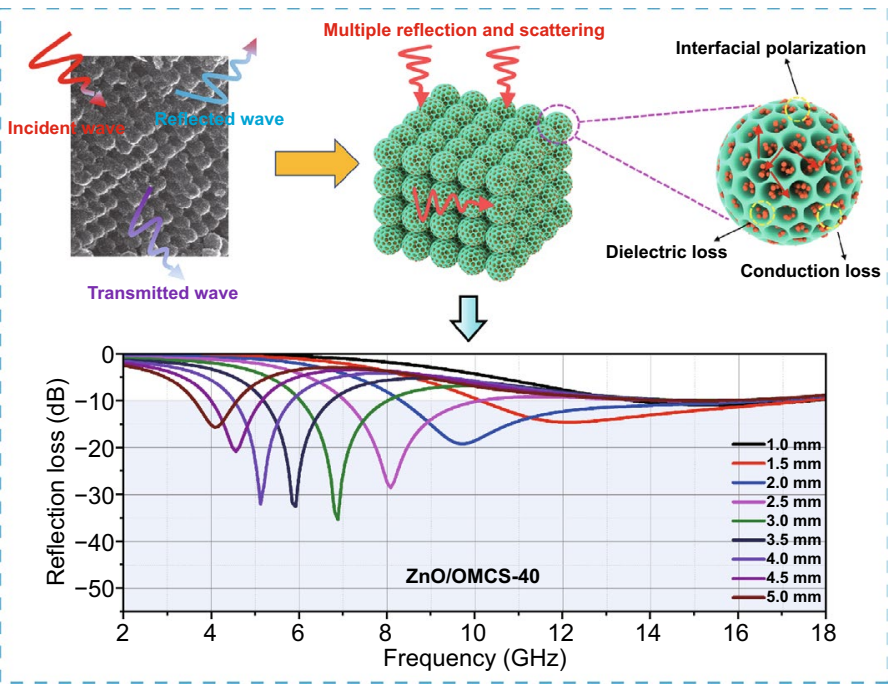
to the well-dispersed ultrafine $\mathrm{ZnO}$ NPs and the 3D ordered mesoporous carbon spheres structure. This work opened up a unique way for developing lightweight and high-efficient carbon-based microwave absorbing materials.

KEYWORDS Three-dimensional ordered structure; Mesoporous carbon spheres; Zinc oxide nanoparticles; Microwave absorption

Chengwei Zhang, cwzhang@ hebut.edu.cn; Weibing Guo, gwbingo@163.com; Ye Yuan, yuanyewins@ hotmail.com

1 School of Materials Science and Engineering, Tianjin Key Laboratory of Materials Laminating Fabrication and Interface Control Technology, Hebei University of Technology, Tianjin 300130, People's Republic of China 


\section{Introduction}

Since electromagnetic pollution became serious problem with the explosive development of electronics and wireless communication, the microwave absorption materials have gained great attention because of their ability to absorb and shield electromagnetic radiation [1-4]. At present, microwave absorbing materials feathered with strong absorption, small thickness, wide efficient absorption bandwidth and light weight have been considered as the idea candidate for attenuating electromagnetic energies [5-9].

Carbon materials are representative dielectric loss medium [10-14]. Nanostructured carbon materials, such as carbon black, carbon fibers, carbon nanotubes (CNTs), graphene and porous carbon, have attracted great interests as microwave absorbing materials for their low density and special physical and chemical properties [15-19]. Among them, the porous carbon involved in large pore volume, high-specific surface area and light weight gained much attention. Recent explorations have demonstrated that abundant porous configuration could benefit to the microwave absorbing performance [20-23]. The porous carbon materials, being a mixture of solid and air, could reduce the effective permittivity of carbon, while improve the impedance matching of materials, leading more electromagnetic waves into the structure [24-26]. Meanwhile, the pore structure, especially with three-dimensional porous structure, could extend the microwave transmission path of incident electromagnetic waves, resulting in multi-reflection and scattering in the porous materials [27]. The repeatedly multi-reflection and scattering offers more chance for the media to attenuate electromagnetic energies [28, 29]. Many porous carbon coupled with magnetic fillers such as magnetic ferrite, magnetic alloy, and metal-organic frameworks (MOFs) have been investigated [30-32]. For instance, Liu et al. developed a kind of MOF-derived carbon based nanocomposites. The magnetic nanocomposites reveal minimum $\mathrm{RL}\left(\mathrm{RL}_{\mathrm{min}}\right)$ value of $-46.5 \mathrm{~dB}$ at $3.5 \mathrm{~mm}$ [33]. Yan et al. fabricated three-dimensional $\mathrm{N}$-doped porous carbon foams embedded with CoNi alloy particles (CoNi@PRM-NC) as microwave absorbing materials. The 3D CoNi@PRM-NC achieves a $\mathrm{RL}_{\min }$ value of $-56 \mathrm{~dB}$ at $17.8 \mathrm{GHz}$ while its thickness is only $1.7 \mathrm{~mm}$ [34]. Although amazing microwave absorbing performance has been demonstrated, the large density of magnetic fillers has severely limited their practical applications.

Zinc oxide $(\mathrm{ZnO})$, as a significantly lightweight, favorable dielectric and semi-conductive medium, has been extensively explored as microwave absorbing materials [35-38]. Meanwhile, to large-scale synthesize $\mathrm{ZnO}$ is easily realized and the low cost of preparing process is suitable for commercial application [39-41]. Up to now, some studies focusing on the microwave absorbing performance of porous carbon modified with $\mathrm{ZnO}$ have been reported [42]. For example, Wang et al. constructed a kind of hierarchical $\mathrm{Ni} / \mathrm{ZnO}$ array hybrid nanostructures. The nanocomposites obtained a $\mathrm{RL}_{\min }$ value of $-27.8 \mathrm{~dB}$ at $9.57 \mathrm{GHz}$ with a wide effective absorption bandwidth of $4.2 \mathrm{GHz}$ over $8-12 \mathrm{GHz}$ [35]. Song et al. prepared three-dimensional reduced graphene oxide foams modified with $\mathrm{ZnO}$ nanowires. The $\mathrm{RL}_{\text {min }}$ value of the hybrids can be $-35.1 \mathrm{~dB}$ at $8.3 \mathrm{GHz}$ [43]. These favorable microwave absorbing properties of $\mathrm{ZnO}$ nanocomposites can be mainly attributed to the increase of the effective polarization interfaces [44]. Interfacial polarization is significantly important to microwave attenuation. Interfacial polarization can be improved by enhancing the interface between different dielectric in microwave absorbing materials. The uniform distribution of $\mathrm{ZnO}$ are good for building up the interface of heterostructure. Meanwhile, the microwave impedance matching of porous carbon would be further improved by doping $\mathrm{ZnO}$, which could reduce the reflection microwaves. However, uneven dispensability of $\mathrm{ZnO}$ in porous carbon has been a vexed problem, which may hinder the further improvement of microwave absorbing ability.

Herein, three-dimensional ordered mesoporous carbon spheres modified with ultrafine $\mathrm{ZnO}$ NPs (ZnO/OMCS) was rationally developed as high-performance microwave absorbing materials. The ultrafine $\mathrm{ZnO}$ NPs are uniformly distributed on the surface of three-dimensional ordered mesoporous carbon spheres, which is beneficial to the interfacial polarization and impendence match. Meanwhile, the 3D ordered mesoporous carbon spheres could promote the scattering and multiple reflection of incident microwaves. Thus, the $\mathrm{ZnO/OMCS} \mathrm{nanocomposites} \mathrm{exhibits} \mathrm{excellent} \mathrm{microwave}$ absorption ability and broad effective absorption bandwidth. The microwave attenuation mechanism for $\mathrm{ZnO} / \mathrm{OMCS}$ nanocomposites was also investigated based on polarization loss, complex permittivity, and conductive loss. Furthermore, 
simulated radar cross section (RCS) results further demonstrated the $\mathrm{ZnO} / \mathrm{OMCS}$ nanocomposites outstanding microwave absorbing ability on complex groove structure. This work indicates $\mathrm{ZnO} / \mathrm{OMCS}$ nanocomposites as a promising microwave absorbing candidate material via low-cost and simple industrial processing.

\section{Experimental}

\subsection{Materials}

Methyl methacrylate (MMA, $>99.5 \%$ ) was obtained from Aladdin. Tetraethoxysilane (TEOS, $>98 \%$ ) was purchased from Tianjin Kemiou Chemical Reagent Co., Ltd, which need to further purify by vacuum distillation method. $\mathrm{CH}_{3} \mathrm{OH}$ ( $\geq 99.8 \%), \mathrm{CH}_{3} \mathrm{CH}_{2} \mathrm{OH}(\geq 99.8 \%), \mathrm{Zn}\left(\mathrm{CH}_{3} \mathrm{COO}\right)_{2} \cdot 2 \mathrm{H}_{2} \mathrm{O}$ ( $\geq 99 \%), \mathrm{KOH}(\geq 85 \%), \mathrm{HCl}(37 \%)$, and $\mathrm{HF}(\geq 40 \%)$ were acquired from Tianjin Kemiou Chemical Reagent Co., Ltd Triblock copolymer F127 $\left(\mathrm{EO}_{106} \mathrm{PO}_{70} \mathrm{EO}_{106}\right)$ was obtained from Sigma-Aldrich Chemical Company. Resol $(\mathrm{Mw}<500)$ was prepared by published strategy [45].

\subsection{Synthesis of $\mathrm{ZnO} / \mathrm{OMCS}$}

Scheme 1 shows the synthesis process of $\mathrm{ZnO} / \mathrm{OMCS}$ and the details are as follows. The poly (methyl methacrylate) (PMMA) colloidal crystal used as hard template to fabricate silica inverse opal is firstly fabricated according to the reported method [46]. Silica precursor was prepared by mixing TEOS, $0.1 \mathrm{M} \mathrm{HCl}$ and ethanol with a mass ratio of $1: 1$ : 1.5 under magnetic stirring for $1 \mathrm{~h}$. A piece of PMMA template was soaked in above silica precursor solution and stand still for $1 \mathrm{~h}$. The impregnated PMMA template was then removed from the solution and dried at room temperature, followed by heated at $450{ }^{\circ} \mathrm{C}$ in an oven for $5 \mathrm{~h}$ to remove PMMA template. The obtained silica inverse opal was then applied as second step template. A few pieces of silica template were impregnated in $20 \mathrm{~mL}$ of ethanol solution containing $1 \mathrm{~g}$ of resol and $1 \mathrm{~g}$ of F127. After the ethanol solution was evaporated completely at room temperature, the precursor/silica composite was heated at $100{ }^{\circ} \mathrm{C}$ for $24 \mathrm{~h}$. Under nitrogen atmosphere, the composite is heated at $350{ }^{\circ} \mathrm{C}$ for $5 \mathrm{~h}$ to remove $\mathrm{F} 127$ at a heating rate of $1{ }^{\circ} \mathrm{C} \mathrm{min}-1$. Subsequently, the temperature was raised to $900{ }^{\circ} \mathrm{C}$ at a heating rate of $5^{\circ} \mathrm{C} \mathrm{min}^{-1}$ and kept for $2 \mathrm{~h}$ for carbonization of resol. Next, the prepared carbon/silica composite was immersed in HF solution (5\%) for 3 days to etch the silica template. The produced 3D ordered mesoporous carbon spheres (OMCS) was then used as support to host ZnO NPs by sol-gel method as follows. First, $0.5 \mathrm{~g}$ of OMCS was ultrasonically dispersed in $25 \mathrm{~mL}$ methanol solution containing $0.9 \mathrm{~g}$ of $\mathrm{Zn}\left(\mathrm{CH}_{3} \mathrm{COO}\right)_{2} \bullet 2 \mathrm{H}_{2} \mathrm{O}$ for $1 \mathrm{~h}$. Then, $20 \mathrm{~mL}$ of $0.45 \mathrm{M} \mathrm{KOH}$ methanol solution was slowly added in above methanol solution under magnetic stirring. After $1 \mathrm{~h}$ of reaction, the black powder $\left(\mathrm{Zn}(\mathrm{OH})_{2} / \mathrm{OMCS}\right)$ was collected by filtration. Finally, $\mathrm{ZnO} / \mathrm{OMCS}$ was produced by heating the black powder at $70{ }^{\circ} \mathrm{C}$ overnight. The theoretical $\mathrm{ZnO}$ content in $\mathrm{ZnO} / \mathrm{OMCS}$ composite is $\sim 40 \mathrm{wt} . \%$. For comparison, the composites with lower $\mathrm{ZnO}$ loadings (denoted as $\mathrm{ZnO} / \mathrm{OMCS}-20$ and $\mathrm{ZnO} /$ OMCS-30, the theoretical $\mathrm{ZnO}$ content is $20 \mathrm{wt} . \%$ and 30 wt.\%) were prepared by the same steps but the addition of $\mathrm{Zn}$ source is $0.34 \mathrm{~g}$ and $0.58 \mathrm{~g}$, respectively.

\subsection{Material characterization}

The morphology and structure of samples were characterized by scanning electron microscopy (SEM, JEOL JSM-7100F) and transmission electron microscope (TEM, JEOL JEM-2010, $200 \mathrm{kV}$ ). Powder X-ray diffraction (XRD) data of $\mathrm{ZnO} / O M C S$ was obtained from Rigaku D/ MAX 2200 VPC equipment with $\mathrm{Cu} \mathrm{K} \alpha$ radiation. The Brunauer-Emmett-Teller (BET) data was acquired on Micro-meritics ASAP-2020 instrument. The actual content of $\mathrm{ZnO}$ in composite was obtained by SDT Q-600 equipment. The X-ray photoelectron spectra (XPS) were carried out on PHI 5000 Versa Probe system.

\subsection{Measurements}

The vector network analyzer (Keysight Technologies, N5244B) was employed to measure the basic electromagnetic parameters of all samples. $\mathrm{ZnO} / \mathrm{OMCS}$ nanocomposites were mixed with pure paraffin at the ratio of $3: 7$. The mixture was pressed into a circular ring shape of out diameter of $7.0 \mathrm{~mm}$, inner diameter and height of $3.0 \mathrm{~mm}$. The RL values were carefully calculated according to the measured electromagnetic parameters. RCS values of the multi groove structure were simulated according to the measured electromagnetic parameters. 


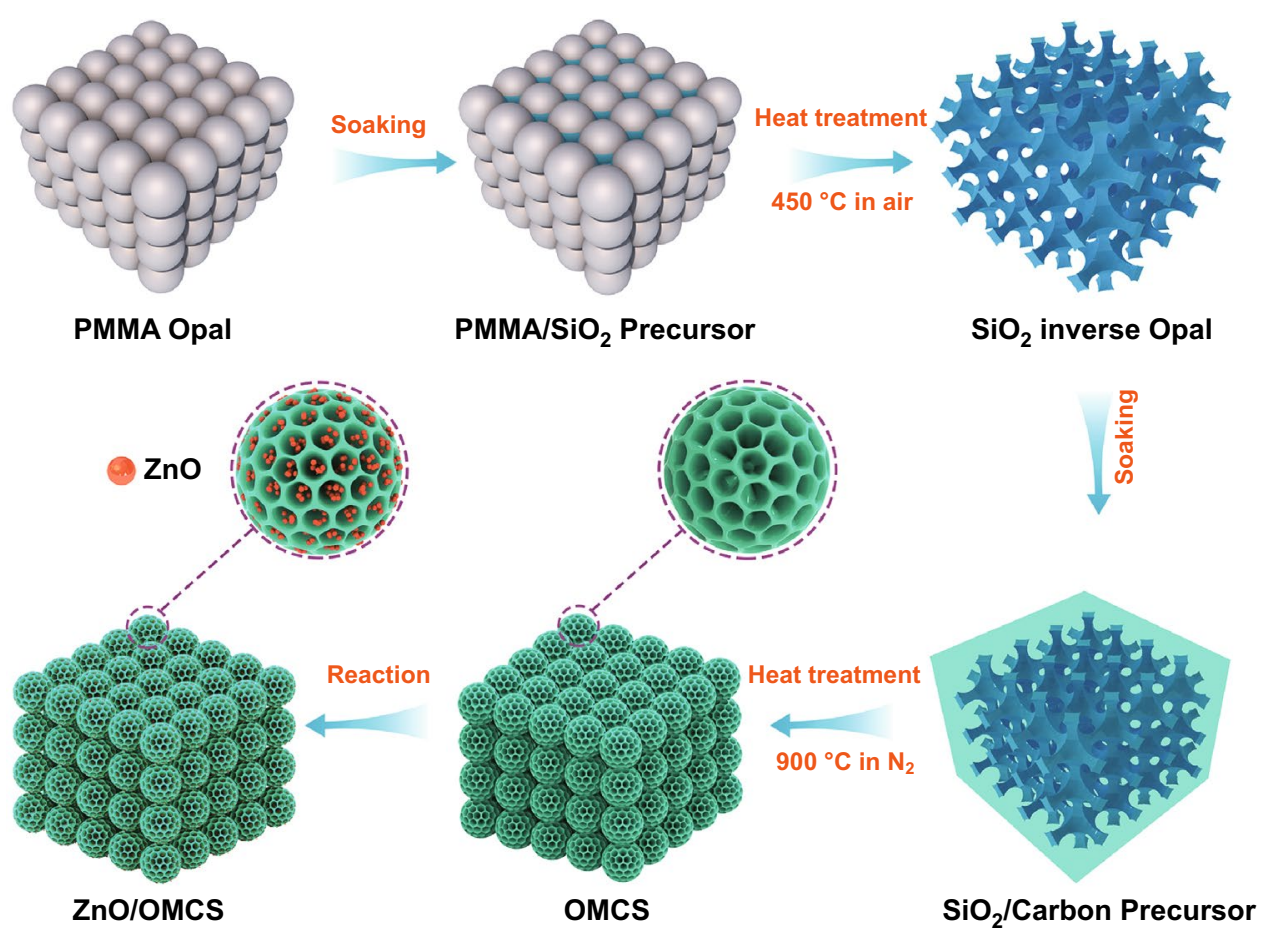

Scheme 1 Schematic illustration on the synthesis of $\mathrm{ZnO} / \mathrm{OMCS}$

\subsection{Calculation details}

The adsorption behavior and electronic structures of graphite/ $\mathrm{ZnO}$ are performed using software of CASTEP, which is constructed based on density functional theory (DFT) [47]. In the calculation process, method of ultrasoft pseudopotentials was used. Exchange-correlation functional of generalized gradient approximation (GGA) in Perdew-BurkeErnzerhof (PBE) was employed. The valence configuration of the calculated atoms was: $2 \mathrm{~s}^{2} 2 \mathrm{p}^{2}$ for $\mathrm{C}, 2 \mathrm{~s}^{2} 2 \mathrm{p}^{4}$ for $\mathrm{O}$, and $3 \mathrm{~d}^{10} 4 \mathrm{~s}^{2}$ for $\mathrm{Zn}$. Cutoff energy for the plane-wave basis was $350 \mathrm{eV}$. The k-point meshing was set to be $6 \times 6 \times 1$ to sample the Brillouin zone. The valence configuration of the calculated atoms were: $2 \mathrm{~s}^{2} 2 \mathrm{p}^{2}$ for $\mathrm{C}, 2 \mathrm{~s}^{2} 2 \mathrm{p}^{4}$ for $\mathrm{O}$, and $3 d^{10} 4 s^{2}$ for Zn. Firstly, graphite (0001) surface slab with three atomic layers was built, and a $16 \AA$-thick vacuum layer was added. To avoid the interaction between neighbor $\mathrm{ZnO}$ molecules, a $2 \times 2 \times 1$ supercell of graphite was constructed. Then a molecule of $\mathrm{ZnO}$ was placed right above the graphite. The model experienced geometry optimization. During the relaxation process, the positions of $\mathrm{C}$ atoms were fixed and molecule of $\mathrm{ZnO}$ could relax freely. The convergence tolerances of energy, maximum displacement, maximum force, and maximum stress are $1.0 \times 10^{-6} \mathrm{eV}$ atom $^{-1}, 1.0 \times 10^{-3} \AA$, $0.03 \mathrm{eV}^{-1}$, and $0.05 \mathrm{GPa}$, respectively.

\section{Results and discussion}

\subsection{Preparation and characterization of $\mathrm{ZnO} / \mathrm{OMCS}$ nanocomposites}

Figure 1a depicts the typical SEM image of PMMA colloidal crystal composed of 3D ordered PMMA spheres (460 $\mathrm{nm}$ in diameter). Figure $1 \mathrm{~b}$ is an SEM image of silica inverse opal fabricated from PMMA template, showing 3D ordered interconnected macropores with average pore size of $410 \mathrm{~nm}$. The silica inverse opal is applied as second template to prepare OMCS, which is shown in Fig. 1c. As can be observed, OMCS demonstrates 3D ordered spherical array structure and the average diameter of the carbon spheres is ca. $380 \mathrm{~nm}$. Because of the condensation of silica and carbon precursor during heating process, the mean size of carbon spheres is smaller than that of the original PMMA spheres after two-step reverse replication procedure. Figure $1 \mathrm{~d}-\mathrm{f}$ displays the SEM images of $\mathrm{ZnO} / O M C S-20, \mathrm{ZnO} / \mathrm{OMCS}$ 30, and $\mathrm{ZnO} / \mathrm{OMCS}-40$ prepared by loading $\mathrm{ZnO}$ NPs on 

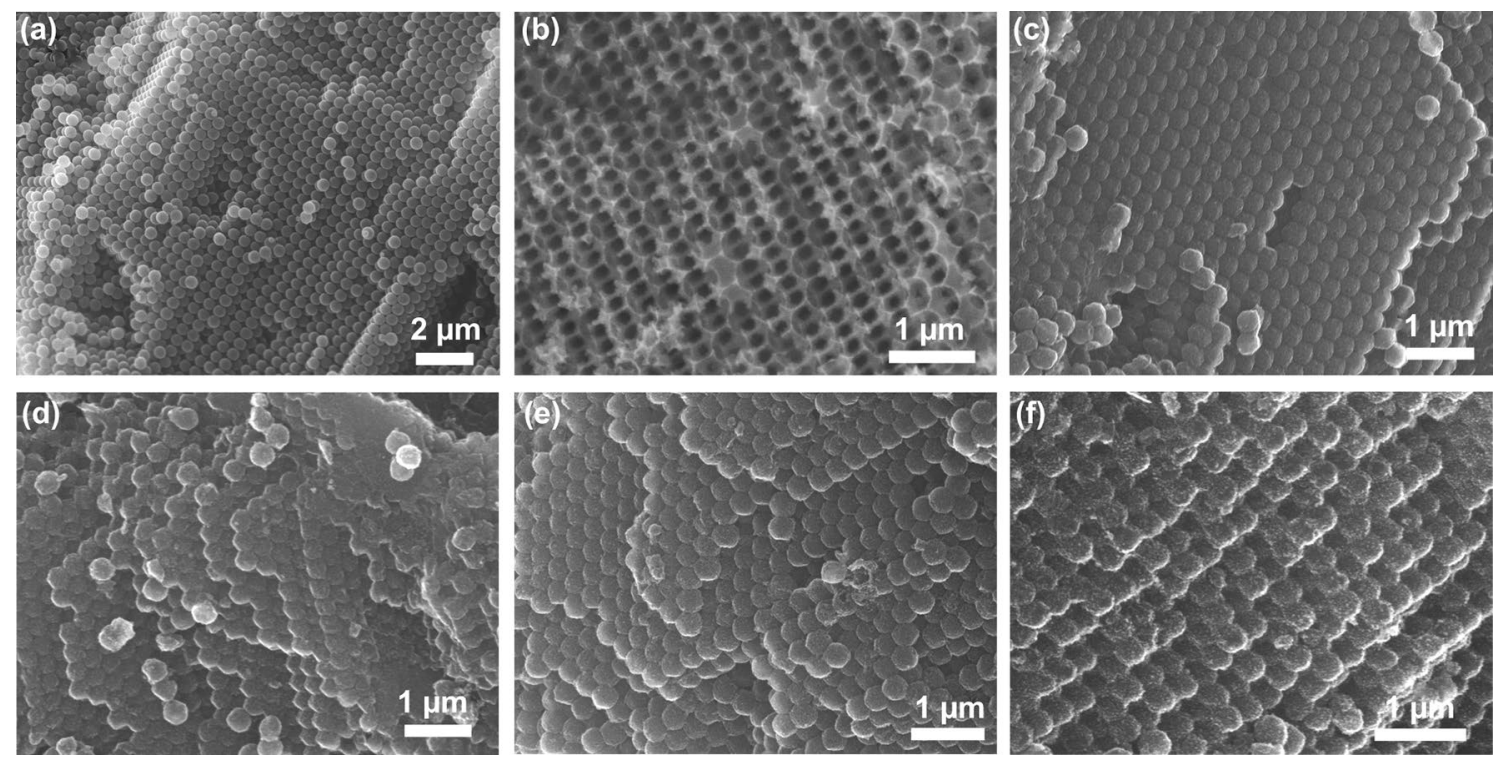

Fig. 1 SEM images of a PMMA opal, b silica inverse opal, c OMCS, d ZnO/OMCS-20, e ZnO/OMCS-30 and f ZnO/OMCS-40

OMCS. It can be found that the closed packed structure of carbon spheres is well preserved, indicating that the loading process of $\mathrm{ZnO}$ would not destroy the 3D ordered structure of OMCS.

TEM was employed to characterize the porous structure of the prepared samples. The low magnification TEM image of OMCS (Fig. 2a) illustrate that ordered mesoporous structure exist in each carbon spheres. The average mesopore size is $\sim 12 \mathrm{~nm}$ calculated from the high magnification TEM image (Fig. 2b). These relatively large mesopores can facilitate the growth of $\mathrm{ZnO}$ NPs on mesoporous walls of OMCS. Figure $2 \mathrm{c}$ shows the TEM image of $\mathrm{ZnO} / \mathrm{OMCS}-40$ and there are no bulk $\mathrm{ZnO}$ can be seen, implying that ZnO NPs are uniformly distributed on carbon spheres. The higher-magnification view of $\mathrm{ZnO} /$ OMCS-40 (Fig. 2d) reveals that the mesoporous structure
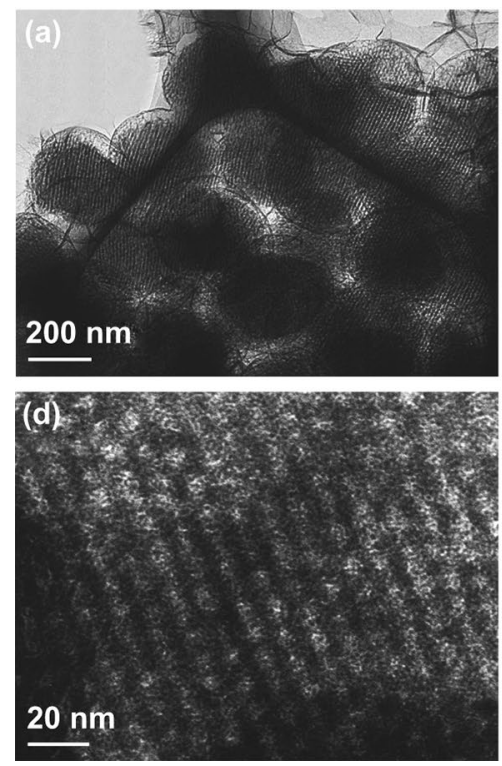
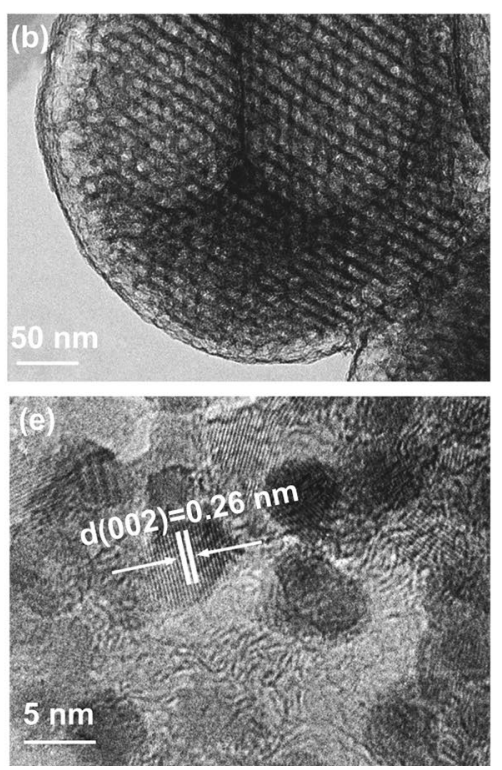
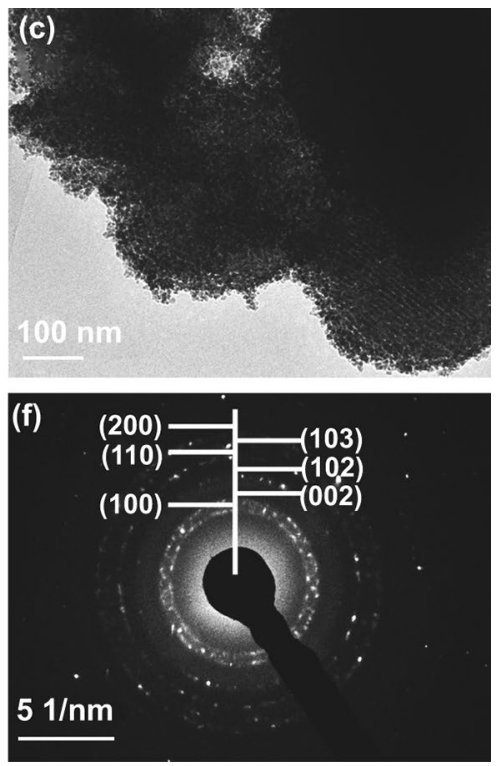

Fig. 2 a, b TEM images of OMCS with different magnifications. c, d TEM images of ZnO/OMCS-40 with different magnifications. e HR-TEM image of $\mathrm{ZnO} / \mathrm{OMCS}-40$. $\mathbf{f}$ The corresponding SAED pattern of $\mathrm{ZnO} / \mathrm{OMCS}-40$ 
still maintained after deposition of ZnO NPs. There preserved mesoporous structure is in favor of the microwave absorbing ability. As can be seen from HR-TEM image of $\mathrm{ZnO} / \mathrm{OMCS}-40$ (Fig. 2e), the $\mathrm{ZnO}$ NPs are uniform in the mean diameter of $\sim 5 \mathrm{~nm}$, and exhibit a polycrystalline wurtzite structure with lattice fringe of $0.26 \mathrm{~nm}$ that assigned to $\mathrm{ZnO}$ (002) plane [37]. The selected area electron diffraction (SAED) pattern with bright and continuous diffraction rings in Fig. $2 \mathrm{f}$ also confirms the polycrystalline behavior of $\mathrm{ZnO}$. Figure $\mathrm{S} 1$ depicts the TEM images of $\mathrm{ZnO} / \mathrm{OMCS}-20$ and $\mathrm{ZnO} / \mathrm{OMCS}-30$ composites and their corresponding SAED patterns. As can be observed from Fig. S1a, c, after loading of $\mathrm{ZnO}$, some mesopores in carbon spheres are still observed. From SAED patterns (Figs. S1b, d and 1f), the diffraction rings composed of dots are getting brighter with the increase of $\mathrm{ZnO}$ content, suggesting more polycrystalline $\mathrm{ZnO}$ on carbon spheres.

The porous structure of OMCS can further be estimated by nitrogen adsorption-desorption isotherms. As shown
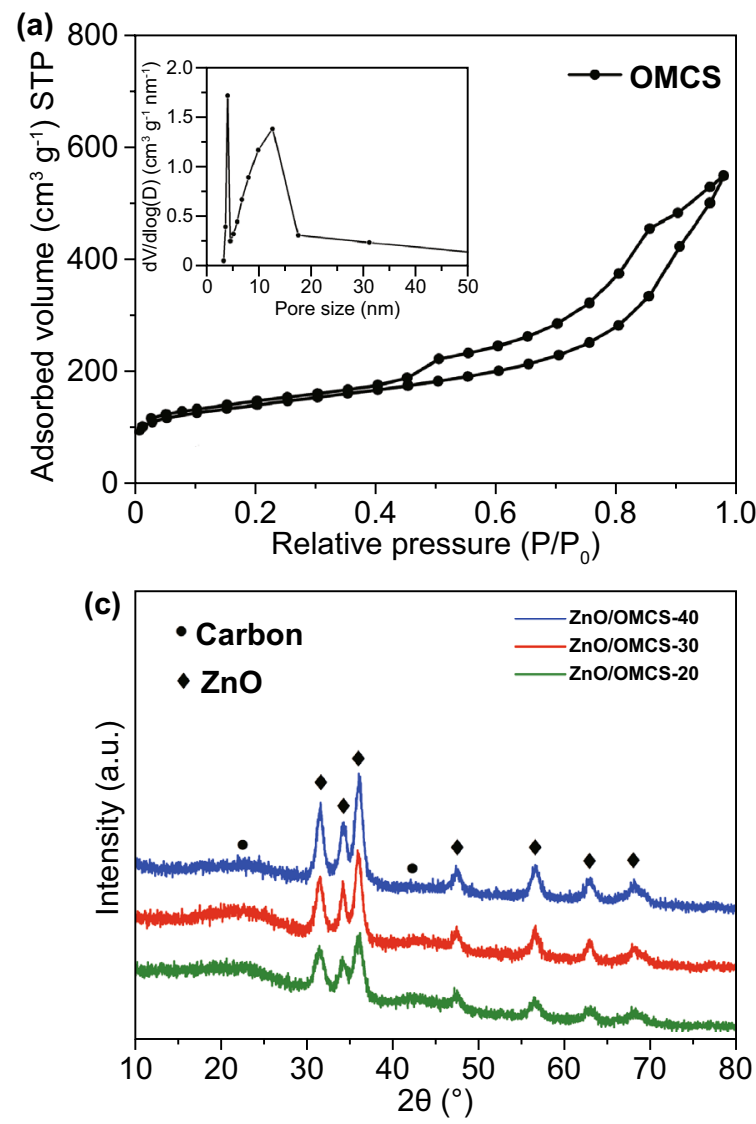

in Fig. 3a, type-IV isotherm and a hysteresis loop of type H1 can be observed, indicating that OMCS possesses mesoporous structure [48]. The BET surface area and pore volume of OMCS are $537.3 \mathrm{~m}^{2} \mathrm{~g}^{-1}$ and $0.72 \mathrm{~cm}^{3} \mathrm{~g}^{-1}$. According to the pore size distribution (PSD) curve derived from nitrogen gas adsorption, the mesopore sizes of OMCS are mainly distributed in the diameter range of $8-15 \mathrm{~nm}$, centered at $12.4 \mathrm{~nm}$. This result is consistent with TEM observation (Fig. 2b). These mesopores can restrict the growth and agglomeration of $\mathrm{ZnO}$ NPs. After loading $\mathrm{ZnO}$ nanoparticles on OMCS, the mesoporous structure still exists, which can be proved by the H1 type hysteresis loops in the isotherms of the $\mathrm{ZnO} / \mathrm{OMCS}$ composites (Fig. S2). $\mathrm{ZnO} /$ OMCS-20 shows a peak located at $5.6 \mathrm{~nm}$ in the PSD curve (inset of Fig. S2), smaller than that of the OMCS, implying that the ZnO NPs are deposited on the mesopore walls of the OMCS. These is no peak in the range of $5-15 \mathrm{~nm}$ in the PSD curves for the $\mathrm{ZnO} / \mathrm{OMCS}-30$ and $\mathrm{ZnO} / \mathrm{OMCS}-40$ composites, which is due to the large amount of $\mathrm{ZnO}$ NPs
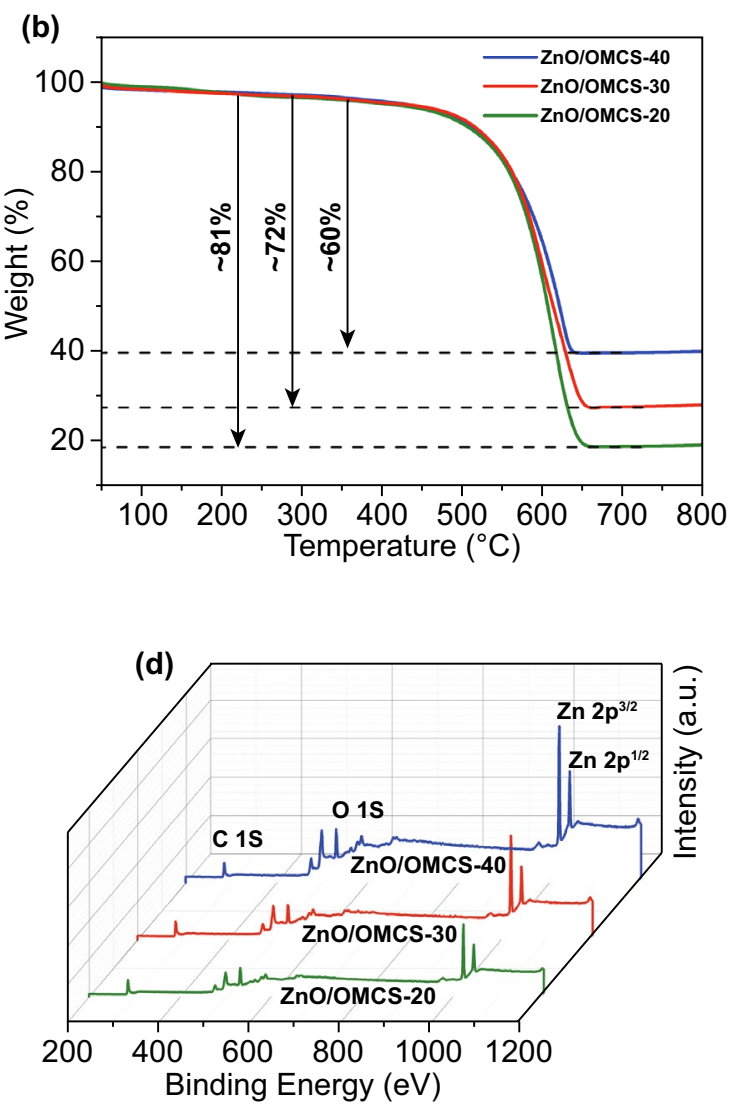

Fig. 3 a $\mathrm{N}_{2}$ adsorption-desorption isotherms and pore size distribution of the OMCS. b TGA profiles, $\mathbf{c}$ XRD patterns, and $\mathbf{d}$ XPS spectra for the $\mathrm{ZnO} / \mathrm{OMCS}-20$, $\mathrm{ZnO} / \mathrm{OMCS}-30$ and $\mathrm{ZnO} / \mathrm{OMCS}-40$ nanocomposites 
that located in the mesopores, destroying the uniformity of mesopores. In addition, the specific surface area and pore volume of the composite decrease with the increase in $\mathrm{ZnO}$ content (Table S1), also confirming that more and more $\mathrm{ZnO}$ NPs are deposited in the mesopores of OMCS.

The actual loading of $\mathrm{ZnO}$ on the OMCS can be evaluated by TGA method and the TGA curves of nanocomposites are shown in Fig. 3b. Each TGA curve shows one weight loss appeared between 450 and $600{ }^{\circ} \mathrm{C}$, corresponding to the oxidation of carbon. The actual contents of $\mathrm{ZnO}$ in the nanocomposites are calculated to be $\sim 19 \%, \sim 28 \%$, and $\sim 40 \%$ for $\mathrm{ZnO} / \mathrm{OMCS}-20$, ZnO/OMCS-30, and ZnO/OMCS-40. This result agrees with the theoretical value, suggesting that the $\mathrm{ZnO}$ content in the nanocomposite can be precisely controlled by the adding amount of $\mathrm{Zn}$ sources.

$\mathrm{XRD}$ is applied to determine the crystal structure of composite, and the XRD patterns for $\mathrm{ZnO} / \mathrm{OMCS}$ composites are shown in Fig. 3c. All XRD patterns show two slight bulges at $2 \theta$ value of $23^{\circ}$ and $43^{\circ}$, assigning to the (002) and (100) reflection of graphitic planes [49]. The other diffraction peaks in the XRD curves correspond to the hexagonal wurtzite structure of $\mathrm{ZnO}$ (JCPDS No. 36-1451) [50]. XRD results also verify that the $\mathrm{ZnO}$ nanoparticles are successfully deposited on carbon spheres. Additionally, XRD can be used to determine the $\mathrm{ZnO}$ crystallite size by applying Scherrer equation from the full width at half maximum (FWHM) of the diffraction peak at $56.5^{\circ}$. After calculating, the crystallite sizes of $\mathrm{ZnO}$ in the composites are 3.6, 4.7, and $5.5 \mathrm{~nm}$ for $\mathrm{ZnO} / \mathrm{OMCS}-20$, $\mathrm{ZnO} / \mathrm{OMCS}-30$, and $\mathrm{ZnO} / \mathrm{OMCS}-40$, respectively. These ultrafine $\mathrm{ZnO}$ NPs are benefit to the multiple reflection and scattering of incident microwave.

The presence of $\mathrm{C}, \mathrm{O}$, and $\mathrm{Zn}$ surface species also can be confirmed by the full survey XPS spectra of $\mathrm{ZnO} / \mathrm{OMCS}$ composites, as shown in Fig. 3d. And there are no other species can be detected, indicating the purity of the composites. In addition, the character peaks of $\mathrm{O}$ and $\mathrm{Zn}$ species are getting stronger during the $\mathrm{ZnO}$ content increasing, verifying the $\mathrm{ZnO}$ nanoparticles has been successfully deposited on the surface of OMCS.

The structure of $\mathrm{ZnO} / \mathrm{OMCS}$ was studied by first-principles calculations to further confirm the experimental results.

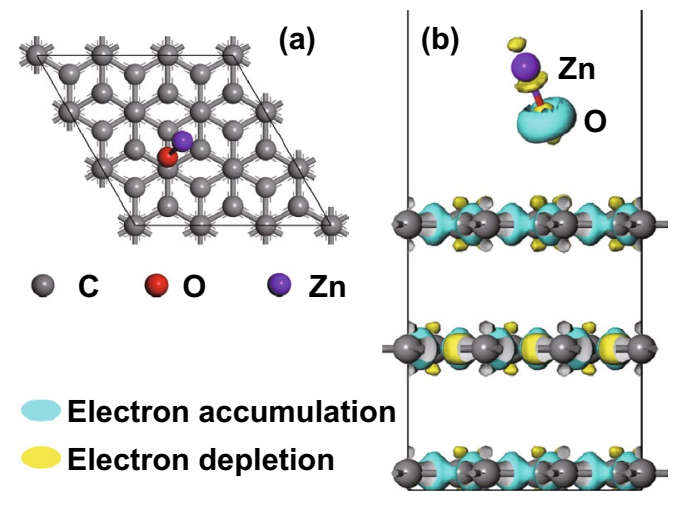

(c)

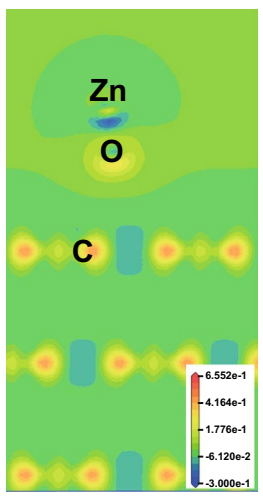

(d)

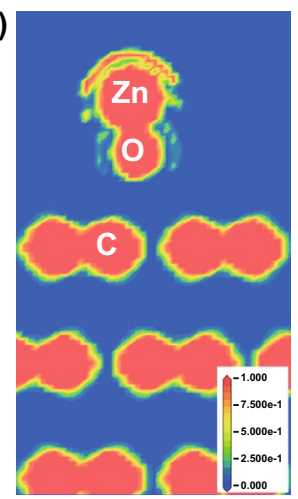

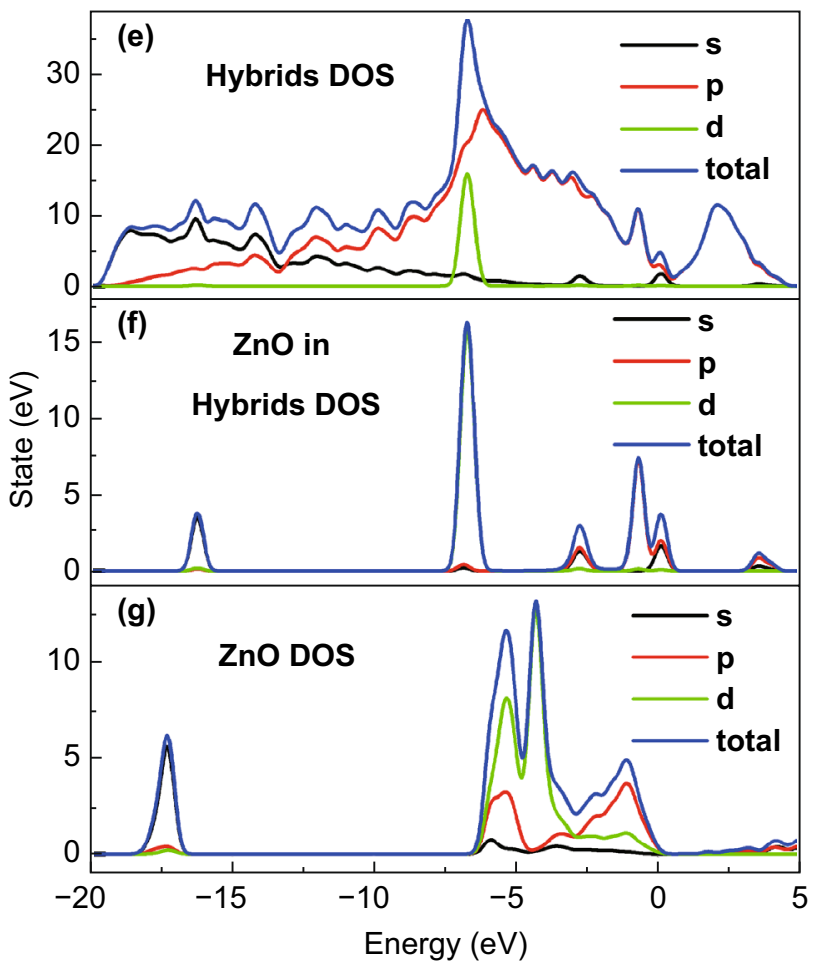

Fig. 4 Simulation results of $\mathrm{ZnO/OMCS.} \mathrm{a} \mathrm{Top} \mathrm{view} \mathrm{of} \mathrm{graphite/ZnO} \mathrm{structure} \mathrm{after} \mathrm{relaxation;} \mathbf{b}$ side view of charge density difference map with isovalue of 0.1 ; slice of $\mathbf{c}$ charge density difference and $\mathbf{d}$ electron localization functional along (011) plane. DOS results for e graphite/ZnO hybrids, $\mathbf{f} \mathrm{ZnO}$ in hybrids, $\mathbf{g}$ bare $\mathrm{ZnO}$ molecule 
The calculated electron density difference map is shown in Fig. 4. Figure $4 \mathrm{a}$ shows the top view of graphite/ $\mathrm{ZnO}$ structure after relaxation. The binding behavior of $\mathrm{ZnO}$ molecule on the graphite (0001) surface is studied with adsorption energy $\left(E_{\mathrm{ad}}\right) . E_{\mathrm{ad}}$ can be obtained by Eq. 1 [51]:

$E_{\text {ad }}=E_{\text {graphite } / \mathrm{ZnO}}-E_{\text {graphite }}-E_{\mathrm{ZnO}}$

where, $E_{\text {graphite/ZnO }}$ is the energy of graphite/ $\mathrm{ZnO}$ structure after relaxation, the $E_{\text {graphite }}$ and $E_{\mathrm{ZnO}}$ are the energies of bare graphite (0001) slab and $\mathrm{ZnO}$ molecule. The adsorption height (h) was also measured. Value of $h$ can be defined as the vertical distance between $\mathrm{O}$ and the topmost $\mathrm{C}$ layer.

The calculated values of $E_{\mathrm{ad}}$ and $h$ are $-3.65 \mathrm{eV}$ and $2.79 \AA$. Figure $4 \mathrm{~b}$ shows the charge density difference map with isovalue of 0.1 . In the map, the light blue color represents charge accumulation area and the yellow color represents charge depletion area. Figure $4 c$ shows slice of charge density difference along (011) plane. From the results of charge density difference, it is found that some valance electrons are transferred from $\mathrm{Zn}$ atom to the $\mathrm{O}$ atom. As a result, $\mathrm{Zn}$ and $\mathrm{O}$ atoms become anions and cations and bonds with each other through electrostatic attraction. Therefore, $\mathrm{Zn}-\mathrm{O}$ bond is typical ionic bond. We also found that $\mathrm{ZnO}$ has influence on the charge distribution on the surface of graphite. A small amount of electrons is transferred from
$\mathrm{C}$ atom to the $\mathrm{O}$ atom. Figure $4 \mathrm{~d}$ shows slice of electron localization functional (ELF) along (011) plane. The data inside the core region are meaningless for the pseudopotentials were used in the calculation process. There are some localized electrons between $\mathrm{Zn}$ and $\mathrm{O}$ atoms, indicating that $\mathrm{Zn}-\mathrm{O}$ bond also has some composition of covalent bond. As to $\mathrm{C}=\mathrm{C}$ bond in the graphite, large amount electrons are found between neighbor $\mathrm{C}$ atoms, which is typical feature of $\pi-\pi$ covalent bond in hexagonal (0001) plane.

The result of density of states (DOS) and partial density of states (PDOS) can provide more information about the nature of interaction between $\mathrm{ZnO}$ and graphite. Figure $4 \mathrm{e}-\mathrm{g}$ shows the DOS results of graphite/ $\mathrm{ZnO}$ hybrids, $\mathrm{ZnO}$ hybrids and bare $\mathrm{ZnO}$ molecule, respectively. Comparing the DOS of bare $\mathrm{ZnO}$, positions of some peaks for $\mathrm{ZnO}$ in graphite/ $\mathrm{ZnO}$ hybrids are changed. What is more, some new peaks appeared, which corresponds to the peaks of graphite. The overlapping confirms the hybridization of $\mathrm{O} 2 \mathrm{sp}, \mathrm{Zn}$ sd, and C 2 sp orbitals.

\subsection{Microwave absorption performance of the $\mathrm{ZnO} /$ OMCS nanocomposites}

The electromagnetic parameters of $\mathrm{ZnO} / \mathrm{OMCS}$ nanocomposites are plotted in Fig. 5 to investigate the effect of
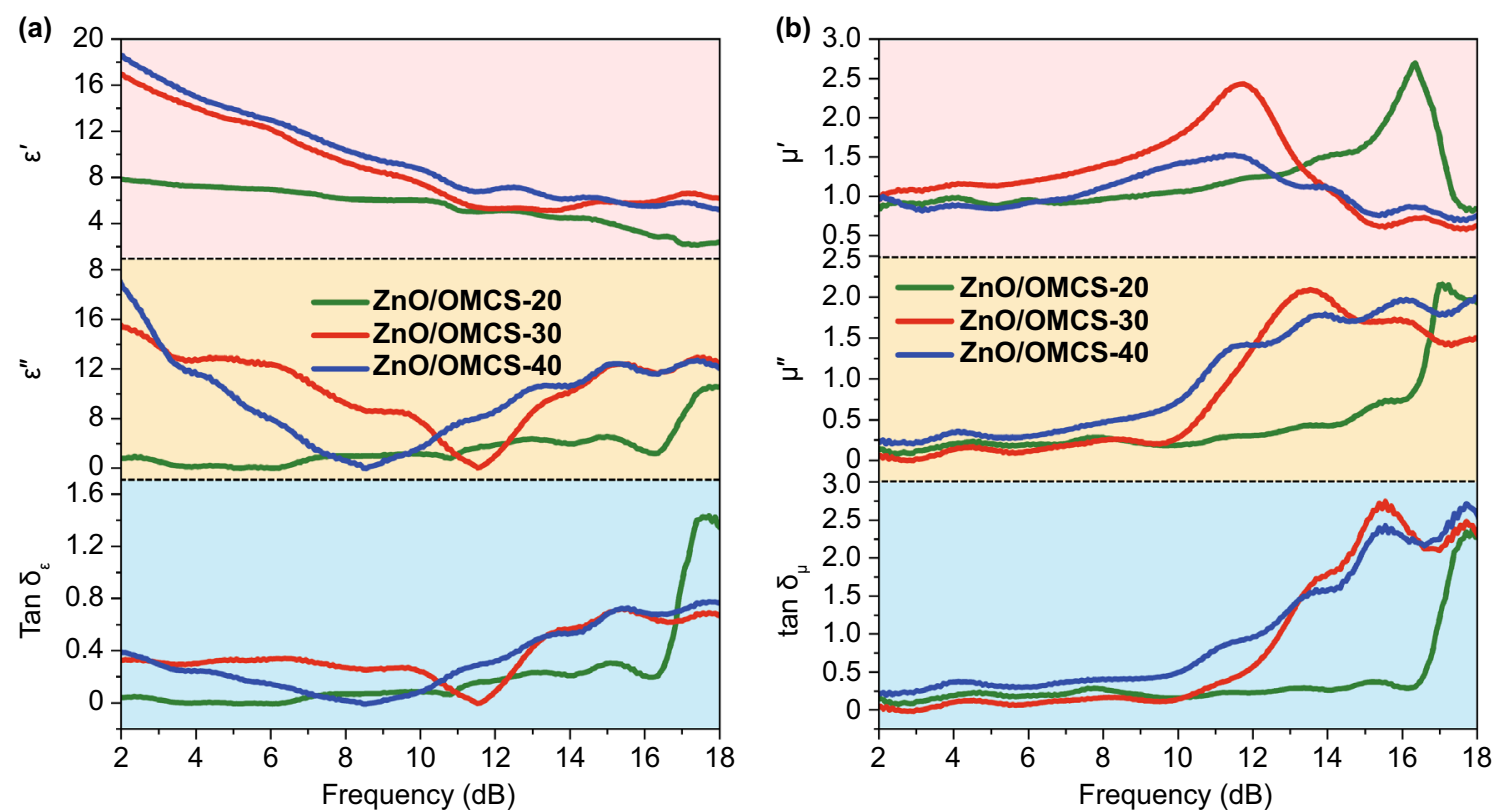

Fig. 5 Frequency dependence of a real part of permittivity, imaginary part of permittivity and tangent dielectric loss values of ZnO/OMCS$20, \mathrm{ZnO} / \mathrm{OMCS}-30$ and $\mathrm{ZnO} / \mathrm{OMCS}-40 \mathrm{~b}$ real parts of permeability, imaginary part of permeability and tangent magnetic loss values of $\mathrm{ZnO} /$ OMCS-20, ZnO/OMCS-30 and ZnO/OMCS-40 
composition and microstructure on microwave absorbing performance. The real part $\left(\varepsilon^{\prime}\right)$ and imaginary part $\left(\varepsilon^{\prime \prime}\right)$ of dielectric constant values of the $\mathrm{ZnO} / \mathrm{OMCS}-20$ vary from 7.9 to 2.1 and 0 to 3.2 , respectively. After introducing more ultrafine $\mathrm{ZnO}$ NPs into OMCS, $\varepsilon$ ' and $\varepsilon^{\prime \prime}$ values of $\mathrm{ZnO} /$ OMCS-30 and $\mathrm{ZnO} / \mathrm{OMCS}-40$ in most of the frequency range reveal a significant increase, indicating the strong dielectric loss ability. According to the previous calculation results of first-principles, the electron density is different between $\mathrm{ZnO}$ and carbon base, which could result in interfacial polarization. The increase in ZnO NPs distributed on the OMCS would not only enhance the associated interfacial polarization, but also build up the active interfaces on the base of 3D ordered porous structure. It is known that the higher $\tan \delta_{\varepsilon}$ value means more dissipation of electromagnetic energy. The $\tan \delta_{\varepsilon}$ values of $\mathrm{ZnO} / \mathrm{OMCS}-30$ and $\mathrm{ZnO} /$ OMCS-40 are heavily intertwined, while their $\tan \delta_{\varepsilon}$ values are larger than that of $\mathrm{ZnO} / \mathrm{OMCS}-20$ in most of the frequency range. This provides the clear evidence that the uniformly distributed ultrafine $\mathrm{ZnO}$ NPs are helpful to enhance the dielectric loss ability. Meanwhile, resonant peaks were observed in the $\varepsilon^{\prime \prime}$ curves of $\mathrm{ZnO} / \mathrm{OMCS}$ nanocomposites. The resonant peaks can be ascribed to the interfacial polarization and dipole polarization at $2-18 \mathrm{GHz}$. According to Debye relaxation theory, the relation between $\varepsilon^{\prime}$ and $\varepsilon^{\prime \prime}$ follows Eq. 2 [52].

$\left(\varepsilon^{\prime}-\frac{\varepsilon_{s}+\varepsilon_{\infty}}{2}\right)^{2}+\left(\varepsilon^{\prime \prime}\right)^{2}=\left(\frac{\varepsilon_{s}-\varepsilon_{\infty}}{2}\right)^{2}$

Generally, a single semicircle derived from the plot of $\varepsilon^{\prime}$ versus $\varepsilon^{\prime \prime}$ was regarded as the Cole-Cole semicircle. Every semicircle represents one Debye relaxation process. Once a polarization relaxation process happens, Eq. 2 can be used to describe the relationship between $\varepsilon^{\prime}$ and $\varepsilon^{\prime \prime}$.
The plots of $\varepsilon^{\prime}-\varepsilon^{\prime \prime}$ curves of ZnO/OMCS nanocomposites were shown in Fig. 6. Obviously, the plots of ZnO/OMCS-20 in Fig. 6a reveal less distorted Cole-Cole semicircles than that of $\mathrm{ZnO} / \mathrm{OMCS}-30$ and $\mathrm{ZnO} / \mathrm{OMCS}-40$. This indicates a stronger polarization relaxation occurs in $\mathrm{ZnO} / \mathrm{OMCS}$ 30 and $\mathrm{ZnO} / \mathrm{OMCS}-40$, which generated at the interfaces between $\mathrm{ZnO}$ NPs and 3D porous carbon base. The dependences of $\mu^{\prime}$ and $\mu^{\prime \prime}$ at 2-18 GHz of $\mathrm{ZnO} / O M C S$ nanocomposites are shown in Fig. 5b. The $\mu^{\prime}$ values of $\mathrm{ZnO} / \mathrm{OMCS}$ are almost the same in the whole frequency. However, $\mathrm{ZnO} /$ OMCS-30 and ZnO/OMCS-40 possess obviously larger $\mu^{\prime \prime}$ values than that of $\mathrm{ZnO} / \mathrm{OMCS}-20$ since $10.2 \mathrm{GHz}$. This indicates that $\mathrm{ZnO} / \mathrm{OMCS}-30$ and $\mathrm{ZnO} / \mathrm{OMCS}-40$ exhibit the optimized magnetic loss performance. Magnetic loss tangent values show the same trend of $\mu^{\prime \prime}$ values.

The modulus of the normalized characteristic impedance and attenuation constant $(\alpha)$ of $\mathrm{ZnO} / \mathrm{OMCS}$ nanocomposites are further investigated. The modulus of the normalized characteristic impedance $Z=\left|Z_{\text {in }}\right| Z_{0} \mid$ can be calculated according to Eq. 3, which represents the ability of the microwave entering into the absorbing materials. If $Z$ is close to 1 , it indicates the material possess a good impedance matching characteristic. At the thickness of $2 \mathrm{~mm}$, ZnO/OMCS20 represents the worst impedance matching characteristic while $\mathrm{ZnO} / \mathrm{OMCS}-30$ obtains the best impedance matching characteristic (Fig. 7a) [53].

$$
\begin{aligned}
& Z=\left|Z_{\text {in }} / Z_{0}\right|=\sqrt{\left|\mu_{r} / \varepsilon_{r}\right|} \tanh \left[j\left(\frac{2 \pi f d}{c}\right)\right] \sqrt{\mu_{r} \varepsilon_{r}} \\
& R L=20 \log \left|\left(Z_{\text {in }}-Z_{0}\right) /\left(Z_{\text {in }}+Z_{0}\right)\right|
\end{aligned}
$$

Here, $Z_{\text {in }}$ represents the normalized input impedance of the microwave absorbing materials, $Z_{0}$ is the impedance of free space, $\varepsilon_{r}$ and $\mu_{r}$ are the complex permittivity and
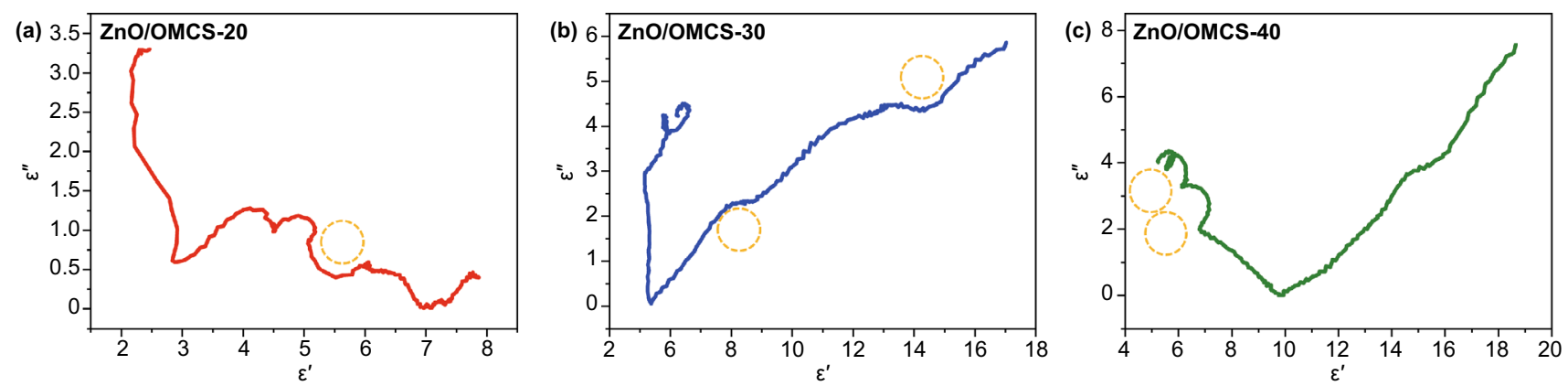

Fig. 6 Typical Cole-Cole semicircles ( $\varepsilon^{\prime}$ vs. $\left.\varepsilon^{\prime \prime}\right)$ for a ZnO/OMCS-20, b ZnO/OMCS-30, c ZnO/OMCS-40 

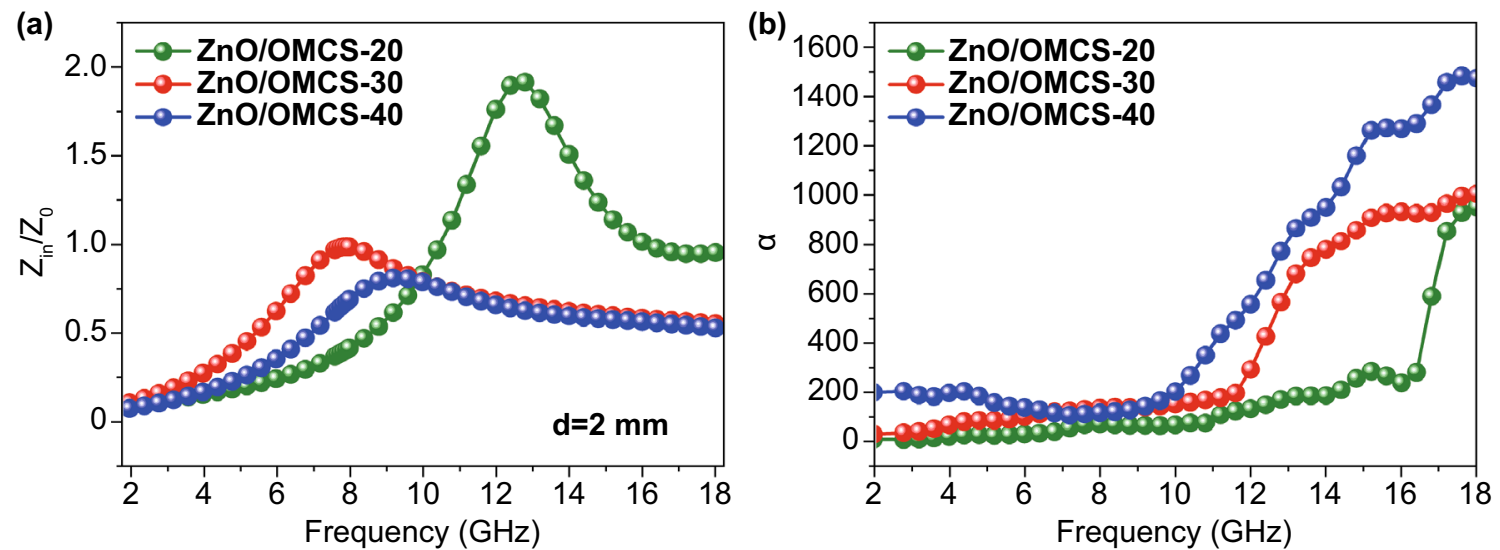

Fig. 7 a Relative input impedance of ZnO/OMCS-20, ZnO/OMCS-30, ZnO/OMCS-40 at $2 \mathrm{~mm}$. b Attenuation constant of ZnO/OMCS-20, $\mathrm{ZnO} / \mathrm{OMCS}-30, \mathrm{ZnO} / \mathrm{OMCS}-40$
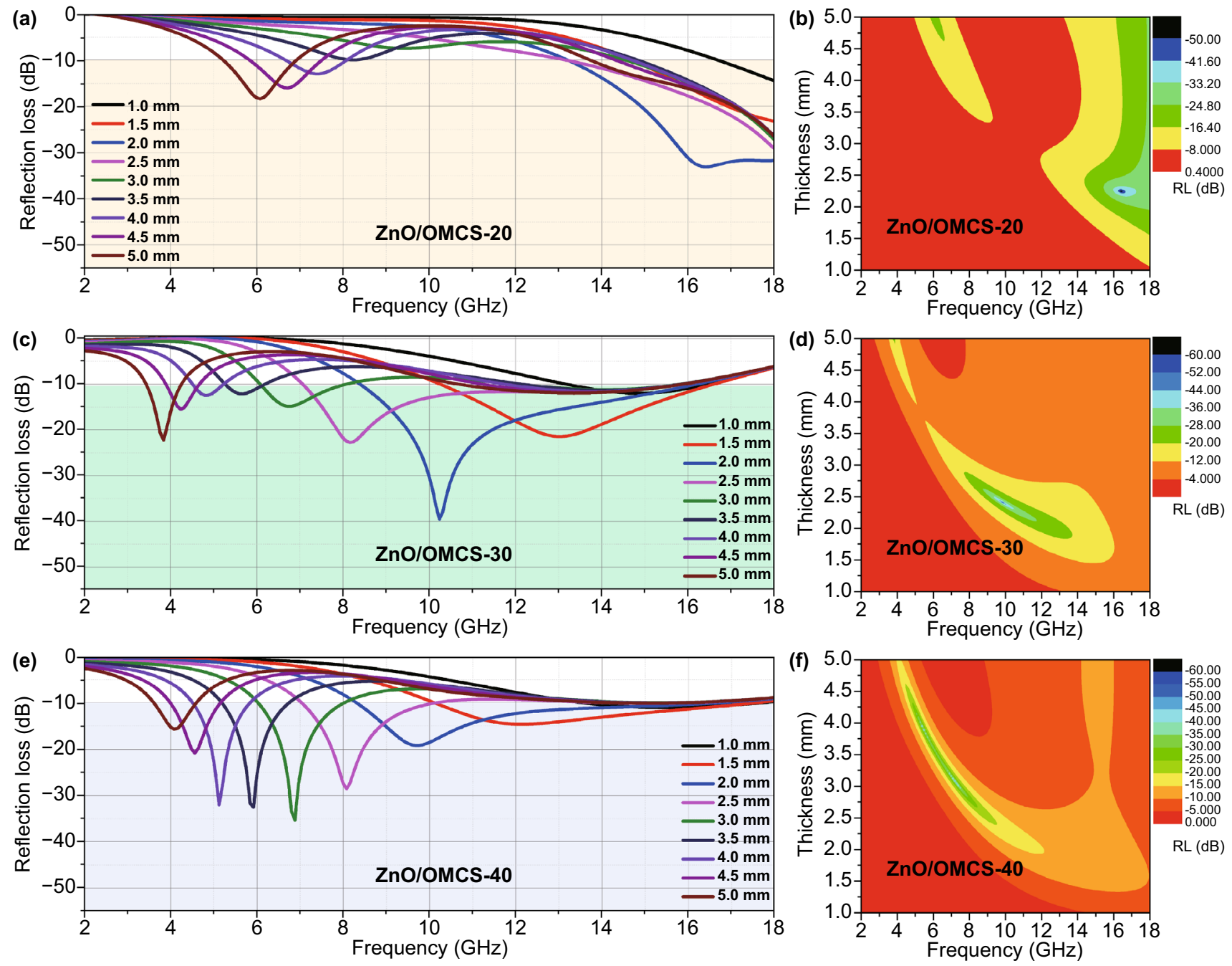

Fig. 8 Reflection loss and Delta value maps of ZnO/OMCS with different ZnO contents. a, b ZnO/OMCS-20; c, d ZnO/OMCS-30; e, f ZnO/ OMCS-40 


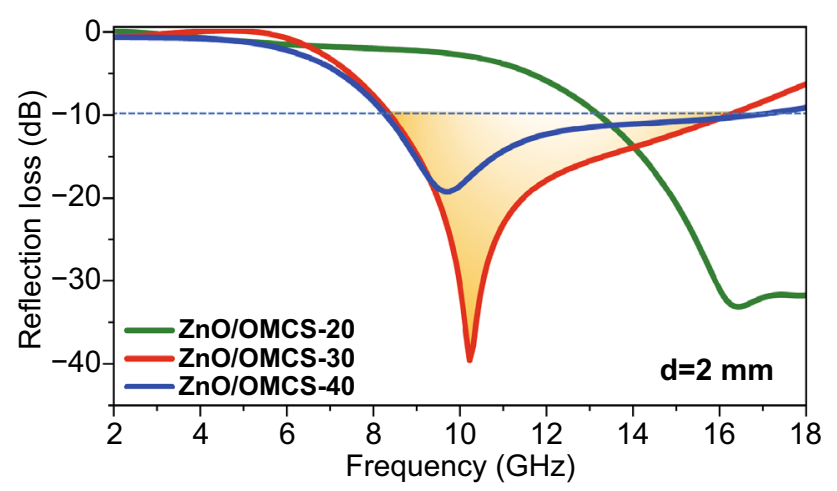

Fig. 9 Reflection loss for $\mathrm{ZnO} / \mathrm{OMCS}$ with different $\mathrm{ZnO}$ contents under a constant thickness of $2 \mathrm{~mm}$

complex permeability, respectively. Attenuation constant $\alpha$ can be expressed as Eq. (5) [54]:

$\alpha=\frac{\sqrt{2} \pi f}{c} \times \sqrt{\left(\mu^{\prime \prime} \varepsilon^{\prime \prime}-\mu^{\prime} \varepsilon^{\prime}\right)+\sqrt{\left(\mu^{\prime \prime} \varepsilon^{\prime \prime}-\mu^{\prime} \varepsilon^{\prime}\right)^{2}+\left(\mu^{\prime} \varepsilon^{\prime \prime}+\mu^{\prime \prime} \varepsilon^{\prime}\right)^{2}}}$

Attenuation constants of $\mathrm{ZnO} / \mathrm{OMCS}$ nanocomposites are shown in Fig. 7b. The order of attenuation constants of three samples is $\mathrm{ZnO} / \mathrm{OMCS}-40>\mathrm{ZnO} / \mathrm{OMCS}-30>\mathrm{ZnO} /$ OMCS-20.

The reflection loss of $\mathrm{ZnO} / \mathrm{OMCS}$ nanocomposites are calculated according to Eq. 4 . The corresponding reflection loss color maps of $\mathrm{ZnO} / \mathrm{OMCS}-20, \mathrm{ZnO} / \mathrm{OMCS}-30$ and $\mathrm{ZnO} / \mathrm{OMCS}-40$ as a function of frequency and thicknesses are shown in Fig. 8. Obviously, ZnO/OMCS-20 exhibits relative poor microwave absorbing performance. Comparatively, ZnO/OMCS-30 exhibits an effective absorption bandwidth of $6.8 \mathrm{GHz}(10.4$ to $17.2 \mathrm{GHz})$ at $1.5 \mathrm{~mm}$, $8.5 \mathrm{GHz}(8.3$ to $16.8 \mathrm{GHz})$ at $2.0 \mathrm{~mm}$ and $9.3 \mathrm{GHz}(7.1$ to $16.4 \mathrm{GHz}$ ) at $2.5 \mathrm{~mm}$ (Fig. 8c, d). The $\mathrm{ZnO} / \mathrm{OMCS}-30$ holds an $\mathrm{RL}_{\min }$ of $-39.3 \mathrm{~dB}$ at the frequency of $10.4 \mathrm{GHz}$ with a small thickness of $2.0 \mathrm{~mm}$, indicating the strong absorption ability [4]. Meanwhile, $\mathrm{ZnO/OMCS-40} \mathrm{also}$ shows a wide absorption bandwidth. It reveals an effective absorption bandwidth of $7.6 \mathrm{GHz}(10.1$ to $17.7 \mathrm{GHz})$ at $1.5 \mathrm{~mm}$ and $9.1 \mathrm{GHz}(8.2$ to $17.3 \mathrm{GHz})$ at $2.0 \mathrm{~mm}$. The reflection loss values of three samples at $2.0 \mathrm{~mm}$ are shown in Fig. 9, which means the microwave absorption performance of $\mathrm{ZnO} / \mathrm{OMCS}$ nanocomposites can be tuned by changing the $\mathrm{ZnO}$ NPs content. The significant feather of $\mathrm{ZnO} / \mathrm{OMCS}$ nanocomposites such as lightweight, strong absorption and wide band width shows it great potential as excellent microwave absorbing materials [14].

The supposed microwave absorbing mechanism of $\mathrm{ZnO} /$ OMCS nanocomposites is as follows (Fig. 10). Firstly, the three-dimensional ordered mesoporous carbon spheres of the carbon base provide abundant solid-air interfaces to realize the impendence matching condition. Second, conduction loss, multiple reflection, and scattering loss of microwaves can be promoted by the $3 \mathrm{D}$ ordered porous structure. Third, the simulation results have demonstrated that the uniform distribution of ultrafine $\mathrm{ZnO}$ NPs is benefit to the polarization interface and the defect-dipoles induced by oxygen vacancies in the $\mathrm{ZnO}$ crystal promotes polarization loss. Generally, it is known that nanoparticles are easily to be self-assembled due to their high surface energy. This aggregation problem can be effectively solved by the threedimensional ordered mesoporous carbon spheres structure. The mesoporous carbon spheres limited the growth of $\mathrm{ZnO}$ NPs, which makes them ultrafine size. Therefore, the $\mathrm{ZnO}$ NPs are effectively separated and distributed in the porous

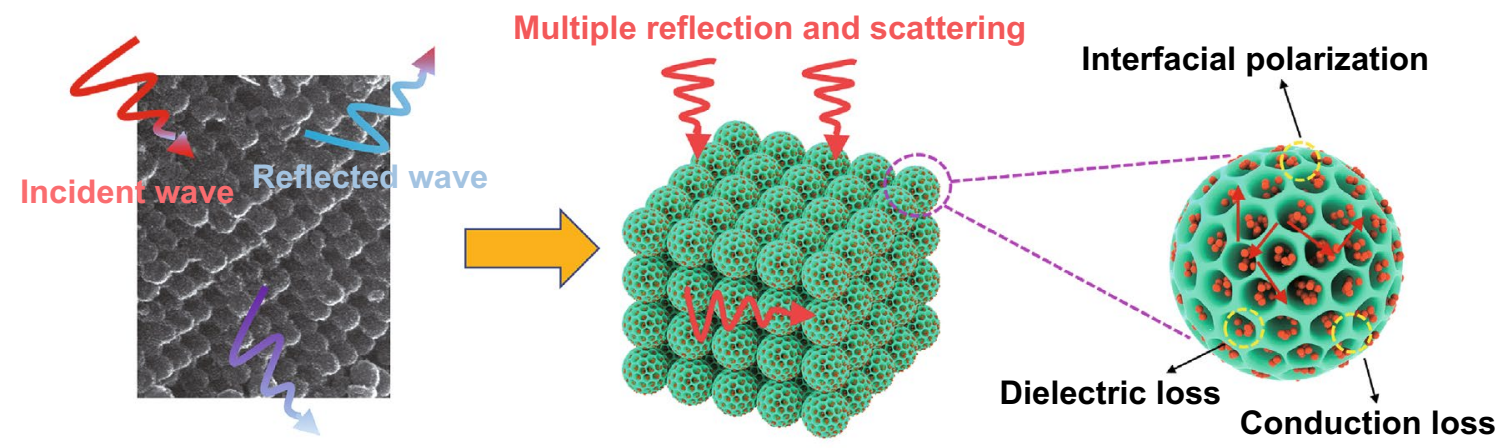

Transmitted wave

Fig. 10 Schematic illustration of the microwave absorbing mechanism of $\mathrm{ZnO} / \mathrm{OMCS}$ 
structure rather than compactly aggregated, which benefits the formation of denser dielectric coupling network and the enhancement of dielectric loss ability. Meanwhile, the threedimensional ordered mesoporous carbon spheres structure can increase the loading ratio of $\mathrm{ZnO}$ NPs. More $\mathrm{ZnO}$ NPs can increase the number of active sites in the nanocomposites, which is good for scattering loss.
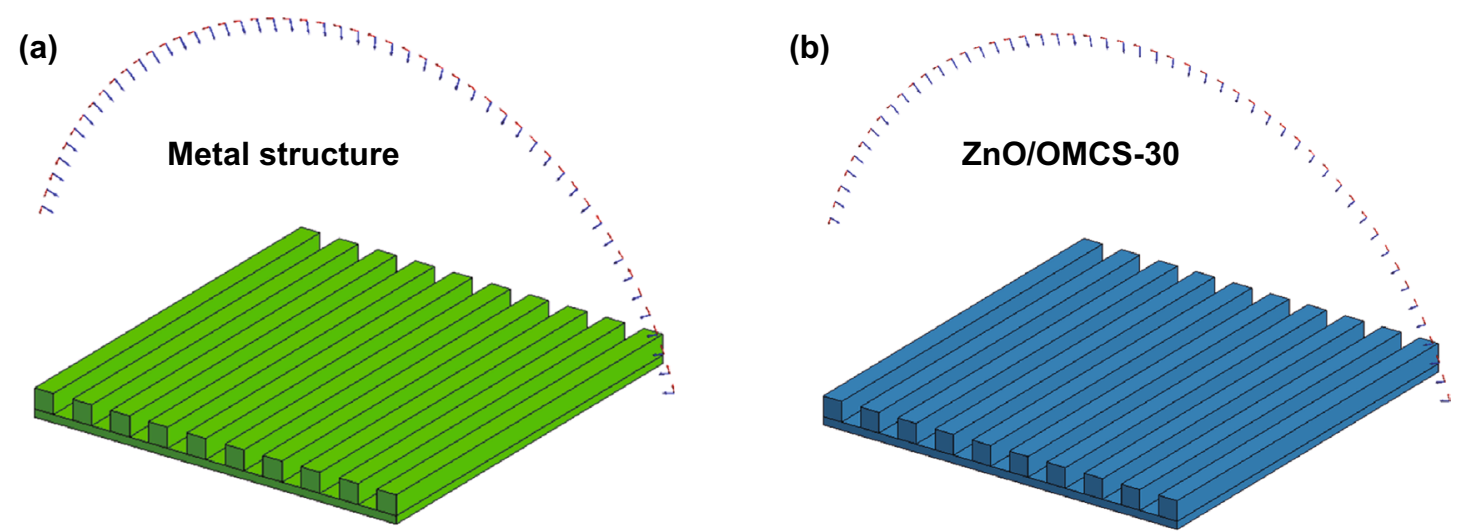

(c) Surface current $\left(\mathrm{mA} \mathrm{m}^{-1}\right)$

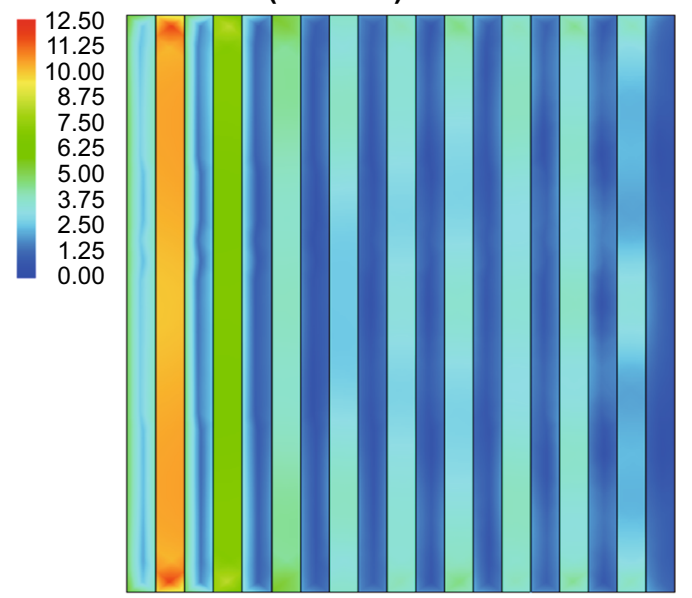

(d) Surface current $\left(\mathrm{mA} \mathrm{m}^{-1}\right)$
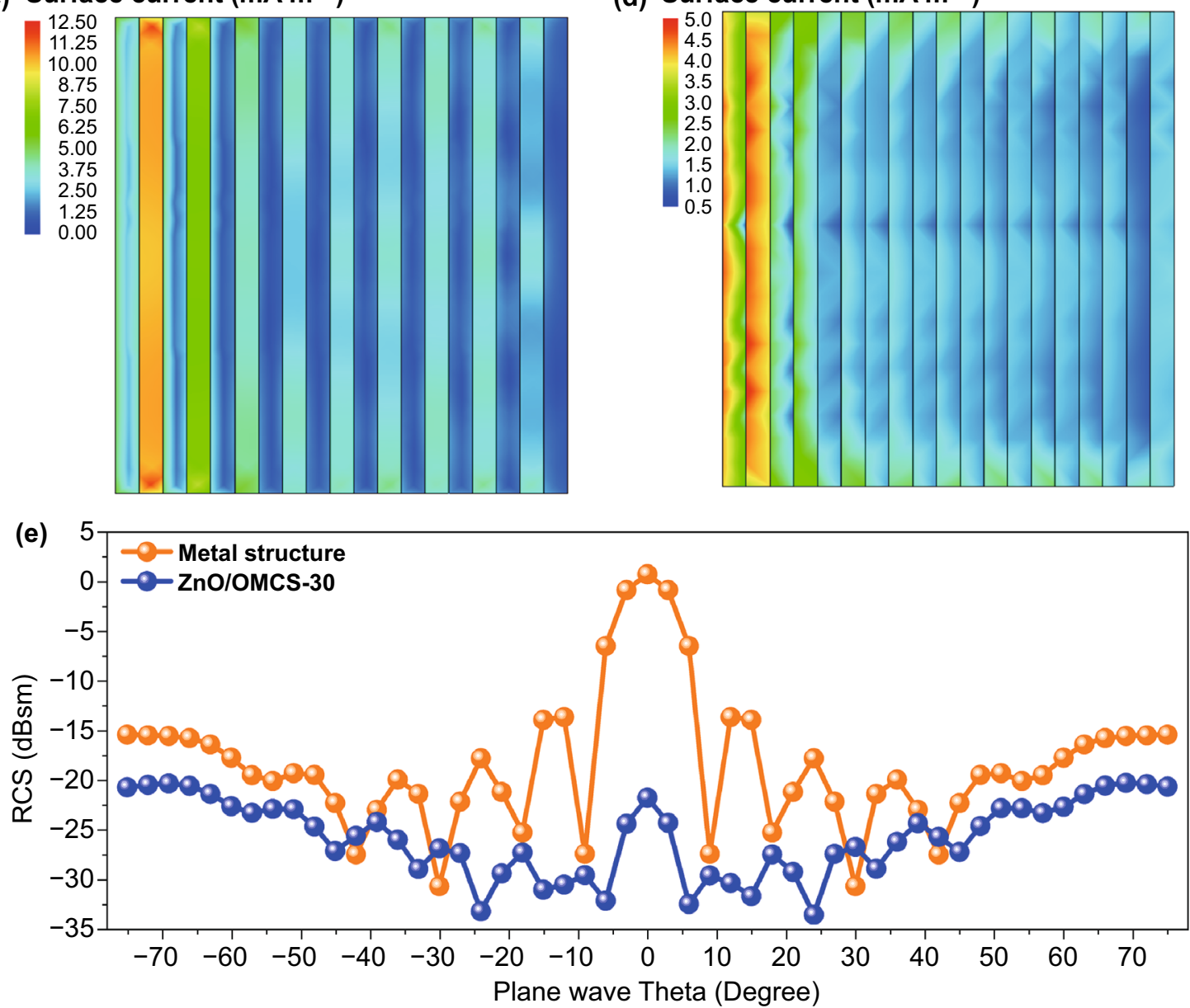

Fig. 11 RCS simulation results of a rectangle metal plate and a rectangle metal plate with ZnO/OMCS. a, b The model of metal plate and metal plate with ZnO/OMCS-30 coatings. c, d Metal plate models and corresponding color maps of simulated current distributions. e RCS values of metal structure and metal structure with $\mathrm{ZnO} / \mathrm{OMCS}$ coatings 


\subsection{Radar cross section}

The rough multiple groove structure is commonly used in ground armor and is a strong electromagnetic scattering source. In order to evaluate the electromagnetic energy dissipation ability of $\mathrm{ZnO} / \mathrm{OMCS}$, the simulation of RCS values of a metal plate with multiple groove structures was selected to demonstrate the microwave absorption performance of $\mathrm{ZnO} / \mathrm{OMCS}$.

$\mathrm{X}$-band radar is widely used and significantly important in national defense [55-57]. Thus, the simulation frequency was chosen at $10.4 \mathrm{GHz}$. The RCS characteristics of the metal groove structures (Fig. 11a) and metal groove structures with $\mathrm{ZnO} / \mathrm{OMCS}-30$ coatings (Fig. 11b), thickness of coating is $2 \mathrm{~mm}$ ) from $-90^{\circ}$ to $+90^{\circ}$ are simulated by method of moment. The simulation procedures are shown in the Supporting Information. The simulated surface current distribution on groove structure are shown in Fig. 11c, d. Clearly, the $\mathrm{ZnO} / \mathrm{OMCS}-30$ coatings effectively suppress the electromagnetic wave scattering on the metal groove structure. The corresponding RCS simulation results are shown in Fig. 11e. It can be observed that the RCS values of metal groove structure with $\mathrm{ZnO} / \mathrm{OMCS}-30$ coatings are much smaller than that of metal groove structure. Generally, the strongest electromagnetic scattering appears at zero degree for plate structure. However, it can be observed that the RCS value at this zero degree was decreased from 1.7 to $-20.6 \mathrm{dBsm}$ after introducing $\mathrm{ZnO} / \mathrm{OMCS}-30$ coatings. These results demonstrated the $\mathrm{ZnO} / \mathrm{OMCS}$ nanocomposites reveal good microwave absorbing ability and could effectively suppress the strong electromagnetic scattering of metal groove structure.

\section{Conclusions}

3D ordered $\mathrm{ZnO} / \mathrm{OMCS}$ nanocomposites were prepared as high-performance microwave absorbing materials. $\mathrm{ZnO} /$ OMCS-30 nanocomposites show effective absorption bandwidth of $9.1 \mathrm{GHz}$ at $2.0 \mathrm{~mm}$ from 8.3 to $16.8 \mathrm{GHz}$ and a strong absorption of $-39.3 \mathrm{~dB}$ at the frequency of $10.4 \mathrm{GHz}$ with a thickness of $2 \mathrm{~mm}$. ZnO/OMCS-40 nanocomposites also exhibit favorable microwave absorbing performance in the lower frequency. RCS simulation demonstrated the $\mathrm{ZnO} /$ OMCS nanocomposites remarkable properties in suppressing strong electromagnetic wave scattering of metal groove structure. The $\mathrm{ZnO} / \mathrm{OMCS}$ nanocomposites with light weight, strong absorption, and wide band width yield various insights into the development of stealth technologies.

Acknowledgements The authors are grateful of the financial support by the National Natural Science Foundation of China (51902083 and 21606068), the Foundation Strengthening Program (2019-JCJQ-142-00), and the Higher Education Science and Technology Research Project of Hebei Province (ZD2019087).

Open Access This article is licensed under a Creative Commons Attribution 4.0 International License, which permits use, sharing, adaptation, distribution and reproduction in any medium or format, as long as you give appropriate credit to the original author(s) and the source, provide a link to the Creative Commons licence, and indicate if changes were made. The images or other third party material in this article are included in the article's Creative Commons licence, unless indicated otherwise in a credit line to the material. If material is not included in the article's Creative Commons licence and your intended use is not permitted by statutory regulation or exceeds the permitted use, you will need to obtain permission directly from the copyright holder. To view a copy of this licence, visit http://creativecommons.org/licenses/by/4.0/.

Electronic supplementary material The online version of this article (https://doi.org/10.1007/s40820-021-00601-x) contains supplementary material, which is available to authorized users.

\section{References}

1. J.C. Shu, M.S. Cao, M. Zhang, X.X. Wang, W.Q. Cao et al., Molecular patching engineering to drive energy conversion as efficient and environment-friendly cell toward wireless power transmission. Adv. Funct. Mater. 30, 1908299 (2020). https:// doi.org/10.1002/adfm.201908299

2. X.H. Liang, Z.M. Man, B. Quan, J. Zheng, W.H. Gu et al., Environment-stable CoxNiy encapsulation in stacked porous carbon nanosheets for enhanced microwave absorption. NanoMicro Lett. 12, 102 (2020). https://doi.org/10.1007/s4082 0-020-00432-2

3. H.Q. Zhao, Y. Cheng, W. Liu, L.J. Yang, B.S. Zhang et al., Biomass-derived porous carbon-based nanostructures for microwave absorption. Nano-Micro Lett. 11, 24 (2019). https ://doi.org/10.1007/s40820-019-0255-3

4. Y. Li, F. Meng, Y. Mei, H. Wang, Y. Guo et al., Electrospun generation of $\mathrm{Ti}_{3} \mathrm{C}_{2} \mathrm{Tx}$ MXene@ graphene oxide hybrid aerogel microspheres for tunable high-performance microwave absorption. Chem. Eng. J. 391, 123512 (2020). https://doi. org/10.1016/j.cej.2019.123512

5. L.L. Song, Y.P. Duan, J. Liu, H.F. Pang, Transformation between nanosheets and nanowires structure in $\mathrm{MnO}_{2}$ upon providing $\mathrm{Co}^{2+}$ ions and applications for microwave absorption. Nano Res. 13, 95-104 (2020). https://doi.org/10.1007/ s12274-019-2578-2 
6. Z. Zhang, J.W. Tan, W.H. Gu, H.Q. Zhao, J. Zheng et al., Cellulose-chitosan framework/polyailine hybrid aerogel toward thermal insulation and microwave absorbing application. Chem. Eng. J. 395, 125190 (2020). https://doi. org/10.1016/j.cej.2020.125190

7. J.C. Shu, X.Y. Yang, X.R. Zhang, X.Y. Huang, M.S. Cao et al., Tailoring MOF-based materials to tune electromagnetic property for great microwave absorbers and devices. Carbon 162, 157-171 (2020). https://doi.org/10.1016/j.carbo n.2020.02.047

8. L.X. Huang, Y.P. Duan, X.H. Dai, Y.S. Zeng, G.J. Ma et al., Bioinspired metamaterials: multibands electromagnetic wave adaptability and hydrophobic characteristics. Small 15, 1902730 (2019). https://doi.org/10.1002/smll.201902730

9. O. Balci, E.O. Polat, N. Kakenov, C. Kocabas, Grapheneenabled electrically switchable radar-absorbing surfaces. Nat. Commun. 6, 6628 (2015). https://doi.org/10.1038/ncomm s7628

10. R.C. Che, L.M. Peng, X.F. Duan, Q. Chen, X.L. Liang, Microwave absorption enhancement and complex permittivity and permeability of $\mathrm{Fe}$ encapsulated within carbon nanotubes. Adv. Mater. 16, 401-405 (2004). https://doi.org/10.1002/ adma.200306460

11. X.F. Zhang, X.L. Dong, H. Huang, Y.Y. Liu, W.N. Wang et al., Microwave absorption properties of the carbon-coated nickel nanocapsules. Appl. Phys. Lett. 89, 053115 (2006). https://doi. org/10.1063/1.2236965

12. L.J. Deng, M.G. Han, Microwave absorbing performances of multiwalled carbon nanotube composites with negative permeability. Appl. Phys. Lett. 91, 023119 (2007). https://doi. org/10.1063/1.2755875

13. W.L. Song, M.S. Cao, Z.L. Hou, X.Y. Fang, X.L. Shi et al., High dielectric loss and its monotonic dependence of conducting-dominated multiwalled carbon nanotubes/silica nanocomposite on temperature ranging from 373 to $873 \mathrm{~K}$ in X-band. Appl. Phys. Lett. 94, 233110 (2009). https://doi. org/10.1063/1.3152764

14. F. Peng, F. Meng, Y. Guo, H. Wang, F. Huang et al., Intercalating hybrids of sandwich-like $\mathrm{Fe}_{3} \mathrm{O}_{4}$-graphite: synthesis and their synergistic enhancement of microwave absorption. ACS Sustain. Chem. Eng. 6, 16744-16753 (2018). https://doi. org/10.1021/acssuschemeng.8b04021

15. M.S. Cao, W.L. Song, Z.L. Hou, B. Wen, J. Yuan, The effects of temperature and frequency on the dielectric properties, electromagnetic interference shielding and microwave-absorption of short carbon fiber/silica composites. Carbon 48, 788-796 (2010). https://doi.org/10.1016/j.carbon.2009.10.028

16. C. Wang, X.J. Han, P. Xu, X.L. Zhang, Y.C. Du et al., The electromagnetic property of chemically reduced graphene oxide and its application as microwave absorbing material. Appl. Phys. Lett. 98, 072906 (2011). https://doi.org/10.1063/1.35554 36

17. G. Li, T.S. Xie, S.L. Yang, J.H. Jin, J.M. Jiang, Microwave absorption enhancement of porous carbon fibers compared with carbon nanofibers. J. Phys. Chem. C 116, 9196-9201 (2012). https://doi.org/10.1021/jp300050u
18. G.X. Wang, Z. Gao, S.W. Tang, C.Q. Chen, F.F. Duan et al., Microwave absorption properties of carbon nanocoils coated with highly controlled magnetic materials by atomic layer deposition. ACS Nano 6, 11009-11017 (2012). https://doi. org/10.1021/nn304630h

19. H.L. Xu, H. Bi, R.B. Yang, Enhanced microwave absorption property of bowl-like $\mathrm{Fe}_{3} \mathrm{O}_{4}$ hollow spheres/reduced graphene oxide composites. J. Appl. Phys. 111, 07A522 (2012). https://doi.org/10.1063/1.3691527

20. B.H. Chang, Y.Z. You, C.X. Hong, X. Xiao, T.C. Liang et al., Carbon fiber aerogel made from raw cotton: a novel, efficient and recyclable sorbent for oils and organic solvents. Adv. Mater. 25, 5916-5921 (2013). https://doi.org/10.1002/ adma.201302435

21. R. Kumar, S.R. Dhakate, T. Gupta, P. Saini, B.P. Singh et al., Effective improvement of the properties of light weight carbon foam by decoration with multi-wall carbon nanotubes. J. Mater. Chem. A 1, 5727-5735 (2013). https://doi. org/10.1039/C3TA10604G

22. Y.L. Ren, C.L. Zhu, S. Zhang, C.Y. Li, Y.J. Chen et al., Three-dimensional $\mathrm{SiO}_{2} @ \mathrm{Fe}_{3} \mathrm{O}_{4}$ core/shell nanorod array/ graphene architecture: synthesis and electromagnetic absorption properties. Nanoscale 5, 12296-12303 (2013). https://doi.org/10.1039/C3NR04058E

23. C.Z. Ping, X. Chuan, M.C. Qun, R.W. Cai, C.H. Ming, Lightweight and flexible graphene foam composites for high-performance electromagnetic interference shielding. Adv. Mater. 25, 1296-1300 (2013). https://doi.org/10.1002/ adma.201204196

24. Y.Y. Lü, Y.T. Wang, H.L. Li, Y. Lin, Z.Y. Jiang et al., MOFderived porous $\mathrm{Co} / \mathrm{C}$ nanocomposites with excellent electromagnetic wave absorption properties. ACS Appl. Mater. Interfaces 7, 13604-13611 (2015). https://doi.org/10.1021/acsam i. $5 \mathrm{~b} 03177$

25. J.H. Luo, Y. Xu, W. Yao, C.F. Jiang, J. Xu, Synthesis and microwave absorption properties of reduced graphene oxidemagnetic porous nanospheres-polyaniline composites. Compos. Sci. Technol. 117, 315-321 (2015). https://doi. org/10.1016/j.compscitech.2015.07.008

26. H.L. Lv, X.H. Liang, G.B. Ji, H.Q. Zhang, Y.W. Du, Porous three-dimensional flower-like $\mathrm{Co} / \mathrm{CoO}$ and its excellent electromagnetic absorption properties. ACS Appl. Mater. Interfaces 7, 9776-9783 (2015). https://doi.org/10.1021/acsam i. 5 b01654

27. K.P. Yuan, R.C. Che, Q. Cao, Z.K. Sun, Q. Yue et al., Designed fabrication and characterization of three-dimensionally ordered arrays of core-shell magnetic mesoporous carbon microspheres. ACS Appl. Mater. Interfaces 7, 5312-5319 (2015). https://doi.org/10.1021/am508683p

28. Y. Zhang, Y. Huang, T.F. Zhang, H.C. Chang, P.S. Xiao et al., Broadband and tunable high-performance microwave absorption of an ultralight and highly compressible graphene foam. Adv. Mater. 27, 2049-2053 (2015). https://doi.org/10.1002/ adma.201405788

29. Y. Yuan, Y.Y. Xiong, J.J. Li, W.L. Yin, Q.Y. Peng et al., Large-scale synthesis of hollow carbon fibers with 
ultra-large diameter by thermally controlled pyrolysis. J. Am. Ceram. Soc. 103, 5629-5637 (2020). https://doi. org/10.1111/jace.17316

30. G.B. Sun, B.X. Dong, M.H. Cao, B.Q. Wei, C.W. Hu, Hierarchical dendrite-like magnetic materials of $\mathrm{Fe}_{3} \mathrm{O}_{4}, \gamma-\mathrm{Fe}_{2} \mathrm{O}_{3}$, and $\mathrm{Fe}$ with high performance of microwave absorption. Chem. Mater. 23, 1587-1593 (2011). https://doi.org/10.1021/cm103 $441 \mathrm{u}$

31. L.J. Wei, C.R. Chao, C.H. Jun, Z. Fan, X. Feng et al., Microwave absorption enhancement of multifunctional composite microspheres with spinel $\mathrm{Fe}_{3} \mathrm{O}_{4}$ cores and anatase $\mathrm{TiO}_{2}$ shells. Small 8, 1214-1221 (2012). https://doi.org/10.1002/ smll.201102245

32. C.W. Zhang, Y. Peng, Y. Song, J.J. Li, F.X. Yin et al., Periodic three-dimensional nitrogen-doped mesoporous carbon spheres embedded with $\mathrm{Co} / \mathrm{Co}_{3} \mathrm{O}_{4}$ nanoparticles toward microwave absorption. ACS Appl. Mater. Interfaces 12, 24102-24111 (2020). https://doi.org/10.1021/acsami.0c03105

33. L. Liu, L. Wang, Q.Q. Li, X.F. Yu, X.F. Shi et al., High-performance microwave absorption of MOF-derived core-shell Co@N-doped Ccarbon anchored on reduced graphene oxide. ChemNanoMat 5, 558-565 (2019). https://doi.org/10.1002/ cnma.201800637

34. J. Yan, Y. Huang, C. Chen, X.D. Liu, H. Liu, The 3D CoNi alloy particles embedded in $\mathrm{N}$-doped porous carbon foams for high-performance microwave absorbers. Carbon 152, 545-555 (2019). https://doi.org/10.1016/j.carbon.2019.06.064

35. S.J. Wang, D.S. Li, Y. Zhou, L. Jiang, Hierarchical $\mathrm{Ti}_{3} \mathrm{C}_{2} \mathrm{~T}_{\mathrm{x}}$ $\mathrm{MXene} / \mathrm{Ni}$ chain/ZnO array hybrid nanostructures on cotton fabric for durable self-cleaning and enhanced microwave absorption. ACS Nano 14, 8634-8645 (2020). https://doi. org/10.1021/acsnano.0c03013

36. J.H. Luo, K. Zhang, M.L. Cheng, M.M. Gu, X.K. Sun, $\mathrm{MoS}_{2}$ spheres decorated on hollow porous $\mathrm{ZnO}$ microspheres with strong wideband microwave absorption. Chem. Eng. J. 380, 122625 (2020). https://doi.org/10.1016/j.cej.2019.122625

37. G.H. He, Y.P. Duan, H.F. Pang, J.J. Hu, Superior microwave absorption based on $\mathrm{ZnO}$ capped $\mathrm{MnO}_{2}$ nanostructures. Adv. Mater. Interfaces 7, 2000407 (2020). https://doi.org/10.1002/ admi. 202000407

38. L.E. Greene, M. Law, J. Goldberger, F. Kim, J.C. Johnson et al., Low-temperature wafer-scale production of $\mathrm{ZnO}$ nanowire arrays. Angew. Chem. Int. Ed. 42, 3031-3034 (2003). https ://doi.org/10.1002/anie.200351461

39. W. Feng, Y.M. Wang, J.C. Chen, L. Wang, L.X. Guo et al., Reduced graphene oxide decorated with in-situ growing $\mathrm{ZnO}$ nanocrystals: facile synthesis and enhanced microwave absorption properties. Carbon 108, 52-60 (2016). https://doi. org/10.1016/j.carbon.2016.06.084

40. M. Cai, A. Shui, X. Wang, C. He, J.J. Qian et al., A facile fabrication and high-performance electromagnetic microwave absorption of $\mathrm{ZnO}$ nanoparticles. J. Alloys Compd. 842, 155638 (2020). https://doi.org/10.1016/j.jallcom.2020.155638

41. P. Claudia, K. Andreas, W. Horst, Self-assembly of $\mathrm{ZnO}$ : from nanodots to nanorods. Angew. Chem. Int. Ed. 41, 1188-1191 (2002). https://doi.org/10.1002/1521-3773(20020402)41:7
42. Y.L. Chen, Z.A. Hu, Y.Q. Chang, H.W. Wang, Z.Y. Zhang et al., Zinc oxide/reduced graphene oxide composites and electrochemical capacitance enhanced by homogeneous incorporation of reduced graphene oxide sheets in zinc oxide matrix. J. Phys. Chem. C 115, 2563-2571 (2011). https://doi. org/10.1021/jp109597n

43. C.Q. Song, X.W. Yin, M.K. Han, X.L. Li, Z.X. Hou et al., Three-dimensional reduced graphene oxide foam modified with $\mathrm{ZnO}$ nanowires for enhanced microwave absorption properties. Carbon 116, 50-58 (2017). https://doi.org/10.1016/j. carbon.2017.01.077

44. D.C. Wei, Y.J. Qi, S.H. Lv, G.M. Shi, Y.X. Dai et al., Facile synthesis of thin coating $\mathrm{C} / \mathrm{ZnO}$ composites with strong electromagnetic wave absorption. Ceram. Int. 45, 4448-4454 (2019). https://doi.org/10.1016/j.ceramint.2018.11.123

45. Y. Meng, D. Gu, F.Q. Zhang, Y.F. Shi, H.F. Yang et al., Ordered mesoporous polymers and homologous carbon frameworks: amphiphilic surfactant templating and direct transformation. Angew. Chem. Int. Ed. 44, $7053-7059$ (2005). https ://doi.org/10.1002/anie.200501561

46. R.C. Schroden, M. Al-Daous, C.F. Blanford, A. Stein, Optical properties of inverse opal photonic crystals. Chem. Mater. 14, 3305-3315 (2002). https://doi.org/10.1021/cm020100z

47. M. Zeng, B. Yang, H. Yan, H. Qu, Y. Hu, Efficient recovery of $\mathrm{Ag}(\mathrm{I})$ from aqueous solution using $\mathrm{MoS}_{2}$ nanosheets: adsorption study and DFT calculation. Chem. Phys. Lett. 757, 137865 (2020). https://doi.org/10.1016/j.cplett.2020.137865

48. A. Sánchez-Sánchez, F. Suárez-García, A. Martínez-Alonso, J.M.D. Tascón, Aromatic polyamides as new precursors of nitrogen and oxygen-doped ordered mesoporous carbons. Carbon 70, 119-129 (2014). https://doi.org/10.1016/j.carbo n.2013.12.080

49. M. Sevilla, A.B. Fuertes, Direct synthesis of highly porous interconnected carbon nanosheets and their application as high-performance supercapacitors. ACS Nano 8, 5069-5078 (2014). https://doi.org/10.1021/nn501124h

50. F.X. Yin, Z. Zhang, Y.G. Zhang, C.W. Zhang, L. Xu, ZnO nanoparticles encapsulated in three dimensional ordered macro-/ mesoporous carbon as high-performance anode for lithium-ion battery. Electrochim. Acta 270, 274-283 (2018). https://doi. org/10.1016/j.electacta.2018.03.073

51. D.B. Putungan, S.-H. Lin, J.-L. Kuo, Metallic $\mathrm{VS}_{2}$ monolayer polytypes as potential sodium-ion battery anode via ab initio random structure searching. ACS Appl. Mater. Interfaces 8, 18754-18762 (2016). https://doi.org/10.1021/acsami.6b03499

52. Y.F. Guo, J.Y. Li, F.B. Meng, W. Wei, Q. Yang et al., Hybridization-induced polarization of graphene sheets by intercalation-polymerized polyaniline toward high performance of microwave absorption. ACS Appl. Mater. Interfaces 11, 17100-17107 (2019). https://doi.org/10.1021/acsami.9b04498

53. H.H. Chen, Z.Y. Huang, Y. Huang, Y. Zhang, Z. Ge et al., Synergistically assembled MWCNT/graphene foam with highly efficient microwave absorption in both $\mathrm{C}$ and $\mathrm{X}$ bands. Carbon 124, 506-514 (2017). https://doi.org/10.1016/j.carbo n.2017.09.007 
54. Y. Cheng, Z.Y. Li, Y. Li, S.S. Dai, G.B. Ji et al., Rationally regulating complex dielectric parameters of mesoporous carbon hollow spheres to carry out efficient microwave absorption. Carbon 127, 643-652 (2018). https://doi.org/10.1016/j. carbon.2017.11.055

55. P. He, M.S. Cao, J.C. Shu, Y.Z. Cai, X.X. Wang et al., Atomic layer tailoring titanium carbide MXene to tune transport and polarization for utilization of electromagnetic energy beyond solar and chemical energy. ACS Appl. Mater. Interfaces 11, 12535-12543 (2019). https://doi.org/10.1021/acsami.9b00593
56. X.A. Li, X.Y. Qu, Z. Xu, W.Q. Dong, F.Y. Wang et al., Fabrication of three-dimensional flower-like heterogeneous $\mathrm{Fe}_{3} \mathrm{O}_{4} /$ Fe particles with tunable chemical composition and microwave absorption performance. ACS Appl. Mater. Interfaces 11, 19267-19276 (2019). https://doi.org/10.1021/acsam i.9b01783

57. X.P. Li, Z.M. Deng, Y. Li, H.B. Zhang, S. Zhao et al., Controllable synthesis of hollow microspheres with Fe@Carbon dualshells for broad bandwidth microwave absorption. Carbon 147, 172-181 (2019). https://doi.org/10.1016/j.carbon.2019.02.073 